\title{
External Quality Control in Ground-Water Sampling and Analysis at the Hanford Site
}

S. H. Hall

S. P. Juracich

November 1991

Prepared for the U.S. Department of Energy under Contract DE-AC06-76RLO 1830

Pacific Northwest Laboratory

Operated for the U.S. Department of Energy by Battalle Memorial Institute 


\title{
DISCLAIMER
}

This report was prepared as an account of work sponsored by an agency of the United States Government. Neither the United States Government nor any agency thereof, nor Battelle Memorial Institute, nor any of their employees, makes any warranty, expressed or implied, or assumes any legal liability or responsibility for the accuracy, completeness, or usefulness of any information, apparatus, product, or process disclosed, or represents that its use would not infringe privately owned rights. Reference hercin to any specific commercial product, process, or service by trade name, trademark, manufacturer, or olherwise does not necessarily constitute or imply its endorsement, recommendation, or favoring by the United States Government or any agency thereof, or Battelle Memorial Institute. The views and opinions of authors expressed herein do not necessarily state or reflect those of the United States Government or any agency thereof.

\author{
PACIFIC NORTHWEST LABORATORY \\ operated by \\ BATTELLE MEMORIAL INSTITUTE \\ for the \\ UNITED STATES DEPARTMENT OF ENERGY \\ under Contract DE-AC06-76RLO 1830
}

Printed in the United States of America

Available to DOE and DOE contractors from the

Office of Scientific and Technical Information, P.O. Box 62, Oak Ridge, TN 37831;

prices available from (615) 576-8401. FTS 626-8401.

Available to the public from the National Technical Information Service,

U.S. Department of Commerce, 5285 Port Royal Rd., Springfield, VA 22161. 
PNL --7836

DE92 004452

EXTERNAL QUALITY CONTROL IN GROUND-WATER SAMPLING AND ANALYSIS AT THE HANFORD SITE

S. H. Hall

S. P. Juracich

November 1991

Prepared for the U.S. Department of Energy under Contract DE-AC06-76RLO 1830

Pacific Northwest Laboratory

Richland, Washington 99352

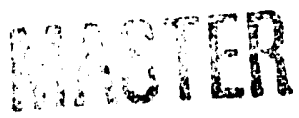


The main purposes for which a client of an analytical laboratory might wish to establish an external quality control (QC) program are 1) to establish or confirm precision and accuracy for measurements reported by the laboratory, and 2) to examine sampling and handling factors that are beyond the control of the 1aboratory. At the U.S. Department of Energy's Hanford Site, external QC for ground-water monitoring is extensive and has included routine submittal of intra- and interlaboratory duplicate samples, blind samples, and several kinds of blank samples. Examination of the resulting QC data for nine of the constituents found in ground water at the Hanford Site shows that the quality of analysis has generally been within the expectations of precision and accuracy that have been established by the U.S. Environmental Protection Agency (EPA). The constituents subjected to review were nitrate, chromium, sodium, fluoride, carbon tetrachloride, tritium, ammonium, trichloroethylene, and cyanide. Of these, the fluoride measurements were notable exceptions and were poor by EPA standards.

The review has shown that interlaboratory analysis of duplicate samples yields the most useful QC data for evaluating laboratory performance in determining commonly encountered constituents. For rarely encountered constituents, interlaboratory comparisons may be augmented with blind samples (synthetic samples of known composition). Intralaboratory comparisons, blanks, and spikes should be generally restricted to studies of suspected or known sample contamination and to studies of the adequacy of sampling and analytical procedures. 


\section{CONTENTS}

SUMMARY . . . . . . . . . . . . . . . . . . . . . . .

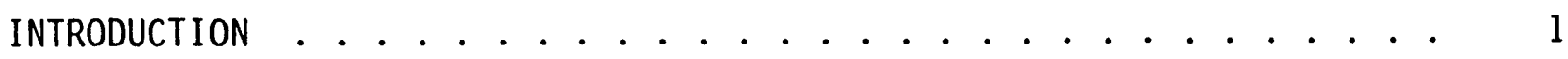
NITRATE .......................... . . . 5 CHROMIUM .......................... . . . 17 SODIUM .......................... . . . 23 FLUORIDE ............................ 27

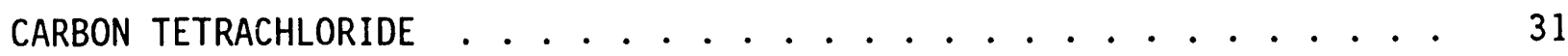
TRITIUM ......................... . . . . . . . . . . . . . .

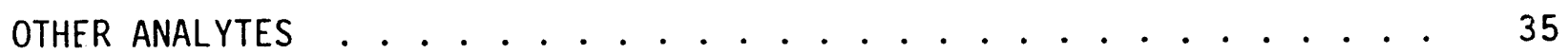
DISCUSSION AND RECOMMENDATIONS .......................... 39 REFERENCES ........................... 43 


\section{FIGURES}

1 Intralaboratory Nitrate Measurements, 0 to $30 \mathrm{mg} / \mathrm{L}$ Range . . . . 7

2 Interlaboratory Nitrate Measurements, 0 to $30 \mathrm{mg} / \mathrm{L}$ Range . . . . 8

3 Intralaboratory Nitrate Measurements, Concentrations Greater Than $30 \mathrm{mg} / \mathrm{L}$. . . . . . . . . . . . . . 10

4 Interlaboratory Nitrate Measurements, Concentrations Greater Than $30 \mathrm{mg} / \mathrm{L}$. . . . . . . . . . . . . . . 11

5 Nitrate Measurements for Blind Samples . . . . . . . . . . 12

6 Intralaboratory Chromium Measurements . . . . . . . . . . . 18

7 Interlaboratory Chromium Measurements . . . . . . . . . . . 19

8 Chromium Measurements for Blind Samples . . . . . . . . . . . 20

9 Interlaboratory Sodium Measurements . . . . . . . . . . . . 25

10 Relative Error Versus Concentration for Sodium

11 Interlaboratory Fluoride Measurements . . . . . . . . . . . 28

12 Intralaboratory Fluoride Measurements . . . . . . . . . . . . 29

13 Fluoride Measurements for Blind Samples . . . . . . . . . . 30

14 Duplicate Carbon Tetrachloride Measurements . . . . . . . . . 32

15 Interlaboratory Tritium Measurements . . . . . . . . . . . . 34

16 Ammonium Measurements for Blind Samples . . . . . . . . . . 36

17 Trichloroethylene Measurements for Blind Samples . . . . . . . . 37

18 Cyanide Measurements for Blind Samples . . . . . . . . . . 38

\section{$\underline{T A B L E}$}

1 Interlaboratory Analytical Precision for Nitrate Measurements . . . 15 


\section{INTRODUCTION}

The primary responsibility for quality control (QC) in chemical analysis lies with the laboratory performing the measurements. Nevertheless, it is considered good practice for clients of the laboratory to conduct independent programs to evaluate the laboratory's performance. The methods used by the laboratory to maintain acceptable limits of precision and accuracy are termed internal $Q C$. A Client's independent program is termed external $Q C$.

There are practical differences in the usefulness of internal and external QC programs. Only the internal program can affect the actual quality of the chemical analysis and can prevent poorly made measurements from being reported. An external program is limited to historical review of the data. On the other hand, the external program is useful for addressing factors that are beyond the control of the laboratory, such as faulty sampling technique, or contamination caused by faulty preservation, handling, or shipping of samples. Thus, the internal and external QC programs are complementary.

In this report, we review Dacific Northwest Laboratory's (PNL) ${ }^{(a)}$ external QC program as it has been applied to environmental ground-water sampling and analysis projects at the Hanford Site during the past 5 years. The program that has been established at PNL is based largely on recommendations from regulatory agencies such as the U.S. Environmental Protection Agency (EPA). The program includes submittal of replicate samples, blind standards, spiked samples, and blanks to both the primary laboratory and a referee 1 aboratory. The magnitude of the program can be inferred from the fact that, at a minimum, one out of five samples submitted for analysis is a QC sample of some type. For comparison, medical laboratories and drinking water laboratories are recertified no more than every 3 months (based on round-robin blind samples).

The perspective taken in this review is that there are only two technical reasons for conducting an external QC program. These are 1) to establish or

(a) PNL is operated for the U.S. Department of Energy by Battelle Memorial Institute 
confirm confidence limits for the data reported by the primary analytical laboratory and 2) to examine those sampling and handling factors beyond the control of the laboratory. Our purpose has been to determine if these two objectives, as applied to a specific project, can be met with a substantially smaller external QC program that would yield a corresponding reduction in analvtical costs. To accomplish this, $Q C$ data for nine contaminants and natural constituents in Hanford ground water were reviewed with respect to the above reasons for conducting an external $Q C$ program and conclusions were drawn using well-known statistical methods.

In reviewing the data, emphasis was placed on the results of duplicate analysis of ground-water samples, and on the analytical precision that can be calculated from such results. Interlaboratory and intralaboratory duplicate measurements were considered separately. (PNL's external QC program has included both intralaboratory duplicate analysis, where identical samples are submitted to one laboratory, and interlaboratory duplicate analysis, where identical samples are submitted to different laboratories.) This study was sponsored by PNL's Ground Water Surveillance Project, which is supported by the U.S. Department of Energy (DOE).

The individual corstituents chosen for this study are nitrate, chromium, sodium, ficoride, carbon tetrachloride, tritium, ammonium, trichloroethylene, and cyanide. Each of these is either a relatively common ground-water constituent at the Hanford Site or illustrates a particular analytical technique or concentration range. In aggregate, these constituents represent a reasonably full range of analytical and QC considerations for ground-water monitoring at the Hanford Site. All of the data used herein represent samples collected by PNL as part of the Resource Conservation and Recovery Act of 1976 (RCRA) projects or the Ground Water Surveillance Project and are available from the electronic data base maintained by PNL for ground-water monitoring projects. The primary analytical laboratory was United States Tesiing Company, Inc. (UST), located in Richland, Washington, and analytical departments within PNL served as referee laboratories.

In the following sections, the nine constituents are discussed. The statistical methods and related assumptions used throughout this study are 
introduced within the context of the measurement of nitrate. A discussion of results is provided along with recommendations to make the external QC program for the Ground Water Surveillance Project more cost effective. 


\section{NITRATE}

Nitrate, which is associated with liquid process wastes, is a widespread contaminant in the ground water of the unconfined aquifer at the Hanford Sicie (Evans et a1. 1989). Ground-water samples are routinely analyzed using the ion chromatographic method described by EPA (1984). Because samples collected at the Hanford Site for the nitrate determination are not preserved, a 48- $h$ maximum holding time prior to analysis (with storage at $4^{\circ} \mathrm{C}$ ) is prescribed. The instrument is calibrated up to $30 \mathrm{mg} / \mathrm{L}$, so samples with higher concentrations must be diluted before measurement. The method is generally capable of resolving nitrate concentrations as low as approximately $0.1 \mathrm{mg} / \mathrm{L}$. However, for contractual reasons, UST has reported al1 concentrations below $0.5 \mathrm{mg} / \mathrm{L}$ as "less than $0.5 \mathrm{mg} / \mathrm{L}$."

Replicate sample sets for nitrate measurement have been periodically collected at field sites. From these samples, duplicate sets were submitted to the primary laboratory and the referee laboratory. Results of duplicate measurements can be used to estimate analytical precision, using the following formulas (Youden 1963; ASTM 1987):

$$
R=\left(d_{1}+d_{2}+d_{3}+\ldots+d_{n}\right) / n
$$

where $R$ is the mean range of duplicate measurements, $d_{x}$ is the absolute value of the difference between first and second measurements for sample number $x$, and $n$ is the number of duplicate sample sets.

$$
s=R / 1.128
$$

where $s$ is the estimate of standard deviation.

In applying these formulas to estimate the precision of an analytical method, it is assumed that the duplicate samples taken for measurement are identical in analyte concentration, that error is normally distributed, and that variability is solely a function of laboratory operations. Then, if the variability reflects a generally accepted performance standard for the 
analytical method, these assumptions are taken as correct; that is, any loss of precision caused by sampling procedures, handling, storage, and so on is taken as negligible.

To ensure meaningful results, the data must be grouped into subsets that can be reasonably expected to display the same degree of variability. For example, samples with a nitrate concentration of less than $30 \mathrm{mg} / \mathrm{L}$ are measured without dilution, but samples having a greater concentration must be diluted. Because of volumetric error associated with performing sample dilution and because the effect of instrument error is magnified in proportion to the dilution factor, results of analysis for diluted samples are expected to be less precise than results for undiluted samples.

Similarly, subsets can be defined based on who is performing the analysis. For example, duplicate measurements made by a single operator within an analytical run (i.e., samples measured "side by side") are expected to display greater apparent precision than results obtained from separate runs. Further, intralaboratory precision is expected to be greater than interlaboratory precision. That is, as more real variables are introduced (e.g., differences in operator skill, volumetric equipment, calibration standards, instrument, choice of dilution factor), observed analytical variability will increase.

Figure 1 represents analytical results for 88 sets of duplicate samples submitted to UST from January 1987 to May 1990 that were measured for nitrate without dilution (i.e., less than $30 \mathrm{mg} / \mathrm{L}$ nitrate). Applying Equations (1) and (2), the calculated standard deviation, excluding the three obvious fliers, is $0.12 \mathrm{mg} / \mathrm{L}$. To meet holding time requirements, the duplicate samples were measured side by side. Each of the three fliers shows a difference of approximately $3 \mathrm{mg} / \mathrm{L}$ between duplicates, and may represent matrix spikes that were not reported as such.

Figure 2 represents analytical results for 53 sets of duplicate samples in the same concentration range. The samples were collected during the same period as the data shown in Figure 1 , but one of the duplicate samples was submitted to UST and the other to PNL. The scatter of these interlaboratory comparison data about the ideal locus of points (a diagonal line, which represents zero difference between duplicate measurements) is, as expected, 


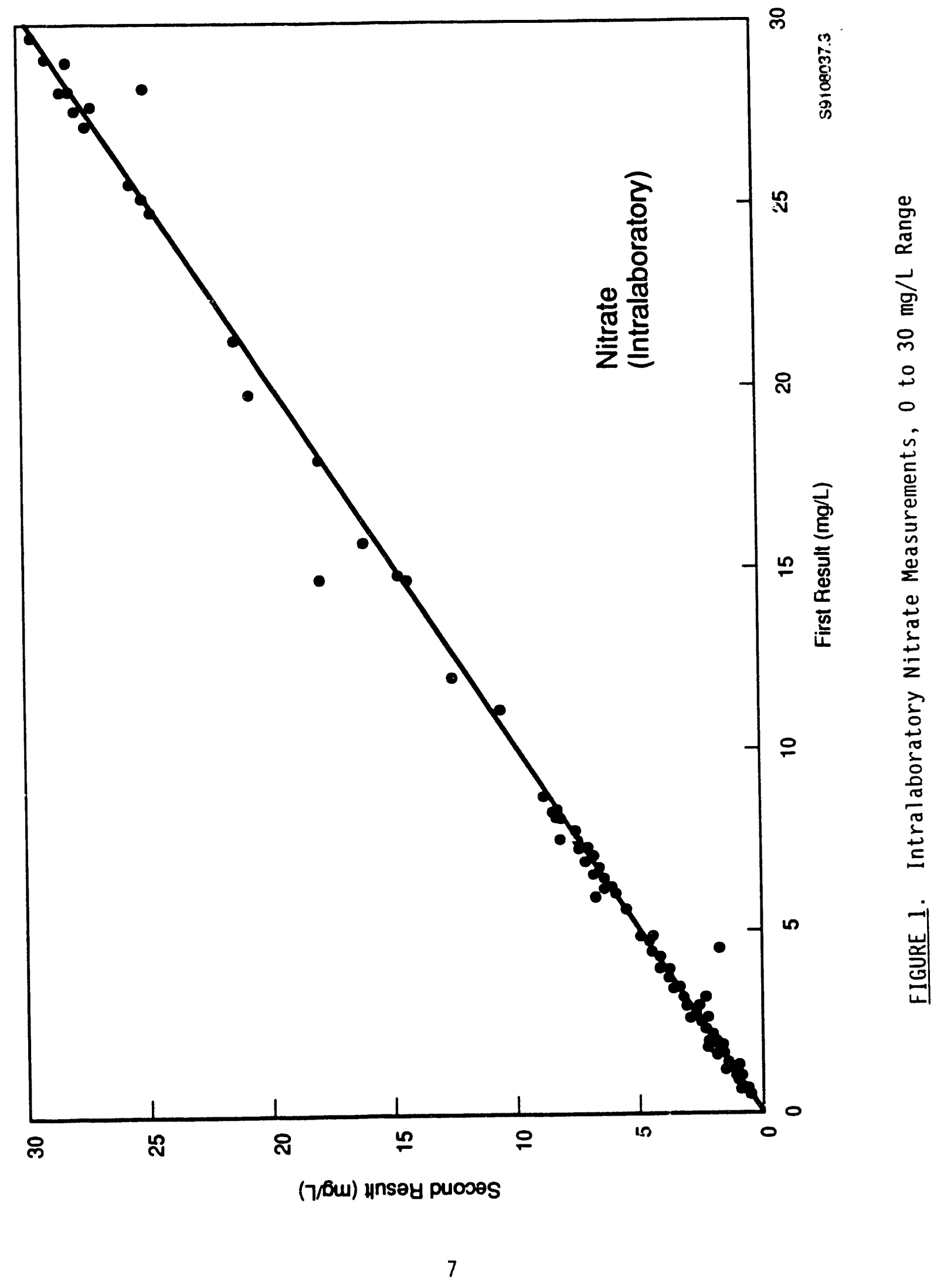




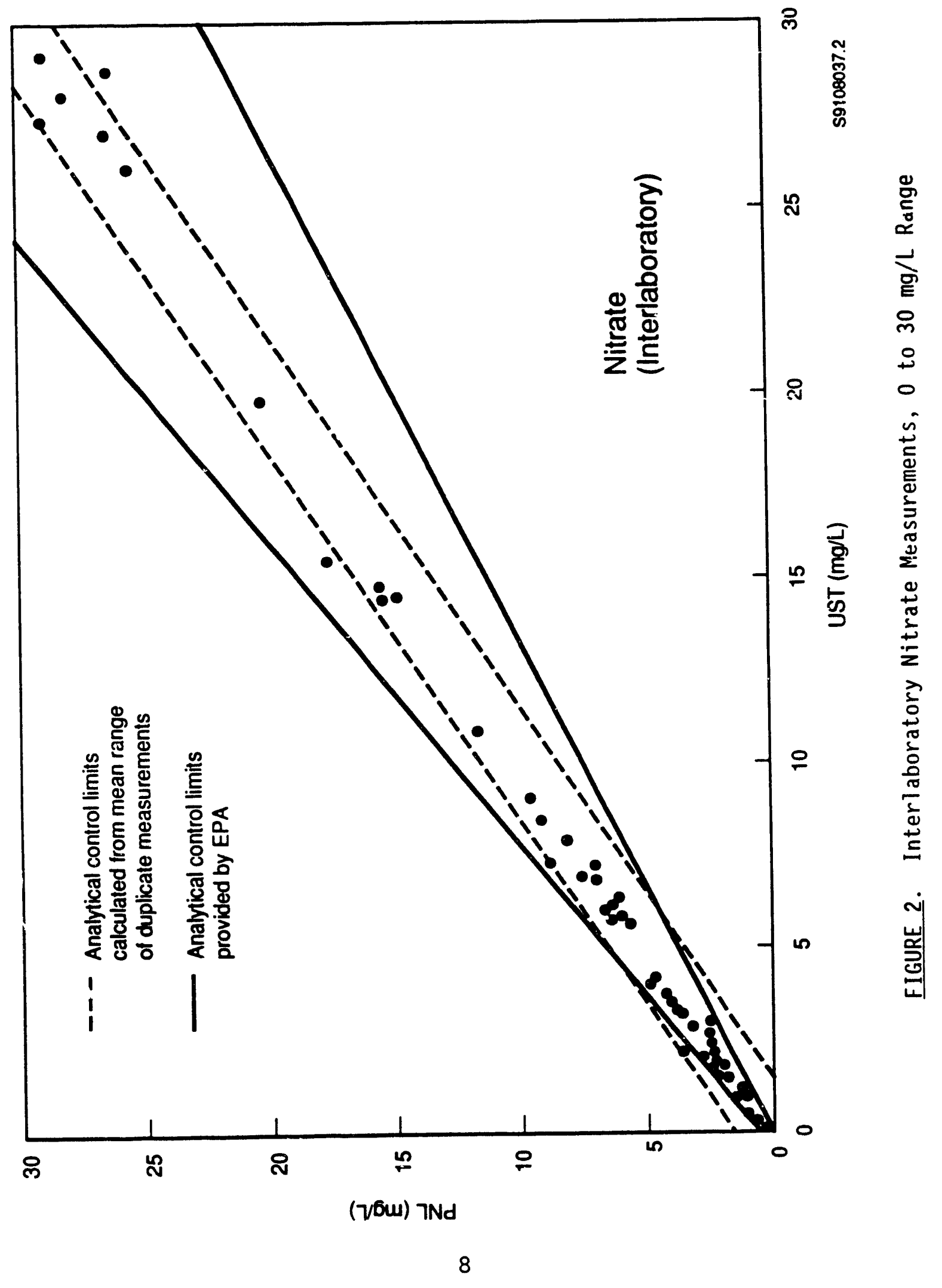


significantly greater than the scatter seen in Figure 1 . The calculated standard deviation for the data shown in Figure 2 is $0.39 \mathrm{mg} / \mathrm{L}$.

Figure 3 shows the results obtained by UST during side-by-side measurement of 52 sets of duplicate samples containing nitrate at more than $30 \mathrm{mg} / \mathrm{L}$. The calculated standard deviation is $2.3 \mathrm{mg} / \mathrm{L}$. Figure 4 shows the corresponding interlaboratory results. The data represented in Figure 4 show much greater variability than the corresponding data in Figure 3 . All of the samplas represented in Figures 3 and 4 required dilution. Because measurement error is partialiy dependent on the degree of dilution required, the data from Figure 4 were grouped according to the most likely dilution factors (actual dilution factors are not available), and the standard deviation was estimated for each of these subgroups using Equations (1) and (2). For the first group, 30 to $60 \mathrm{mg} / \mathrm{L}$, a $1: 1$ dilution factor is assumed, and the calculated standard deviation is $2.0 \mathrm{mg} / \mathrm{L}$. For the second group, 60 to $300 \mathrm{mg} / \mathrm{L}$, a $1: 9$ dilution is assumed, and the standard deviation is $16 \mathrm{mg} / \mathrm{L}$. For the third group, with concentration greater than $300 \mathrm{mg} / \mathrm{L}$, a dilution factor of $1: 24$ is assumed, and the standard deviation is $49 \mathrm{mg} / \mathrm{L}$. In the first and third groups, there are only 10 and 5 duplicate measurements, respectively; so the calculated variabilities must be considered to be approximations. (This treatment of data was not used for the data represented in Figure 3 . Inspection of Figure 3 shows that, compared to Fiyure 4 , the precision appears nearly independent of concentration.)

Figure 5 illustrates analytical results for 10 blind samples submitted to UST since July 1988. The samples ranged from 0.36 to $30.5 \mathrm{mg} / \mathrm{L}$ in concentration. The standard deviation for this set of measurements was calculated as follows:

$$
s=\sqrt{\left(d_{1}^{2}+d_{2}^{2}+d_{3}^{3} \ldots+d_{n}^{2}\right) /(n-1)}
$$

where $d_{x}$ is the difference between measured concentration and known true concentration for sample $x$, and $s$ and $n$ are defined above. 


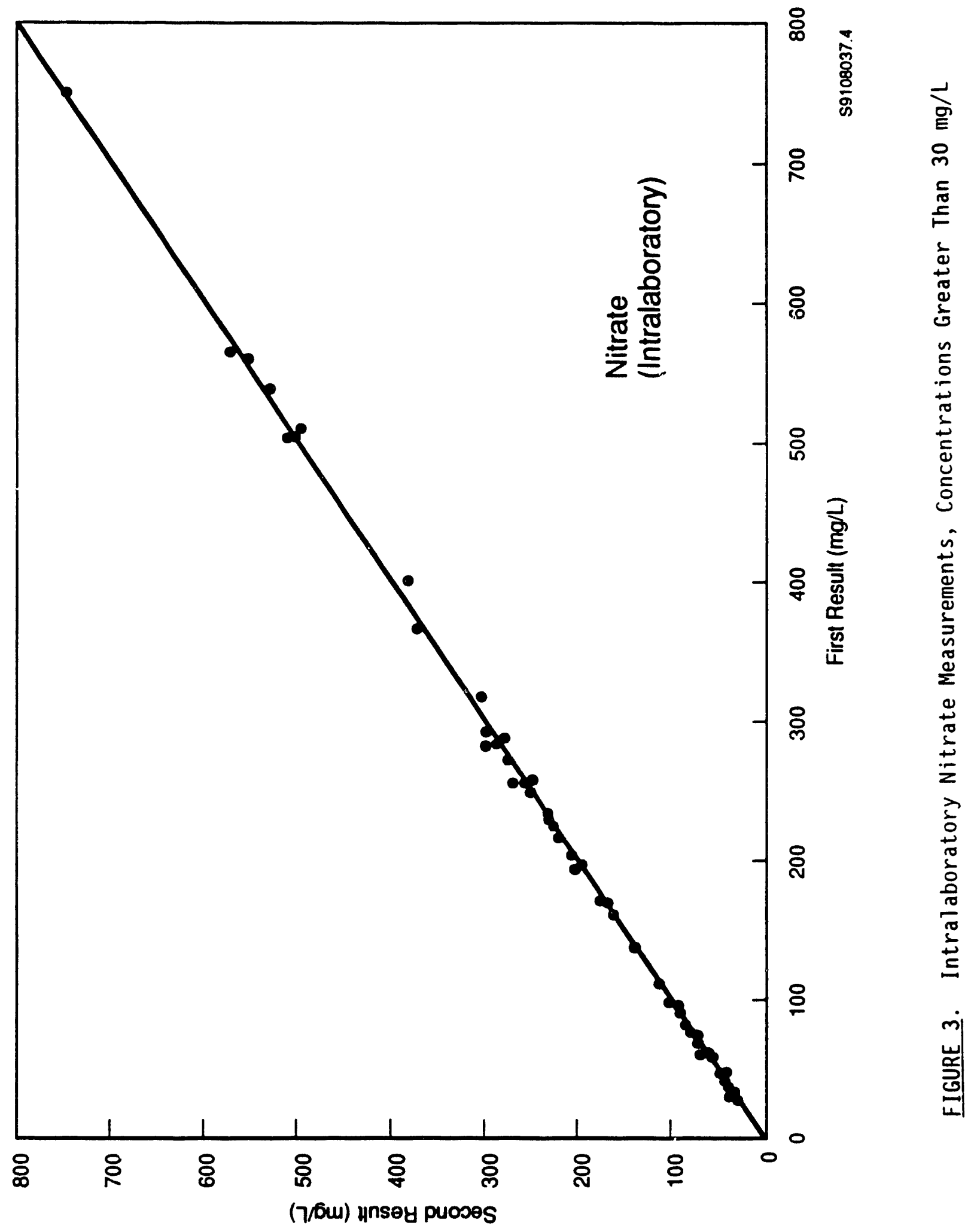




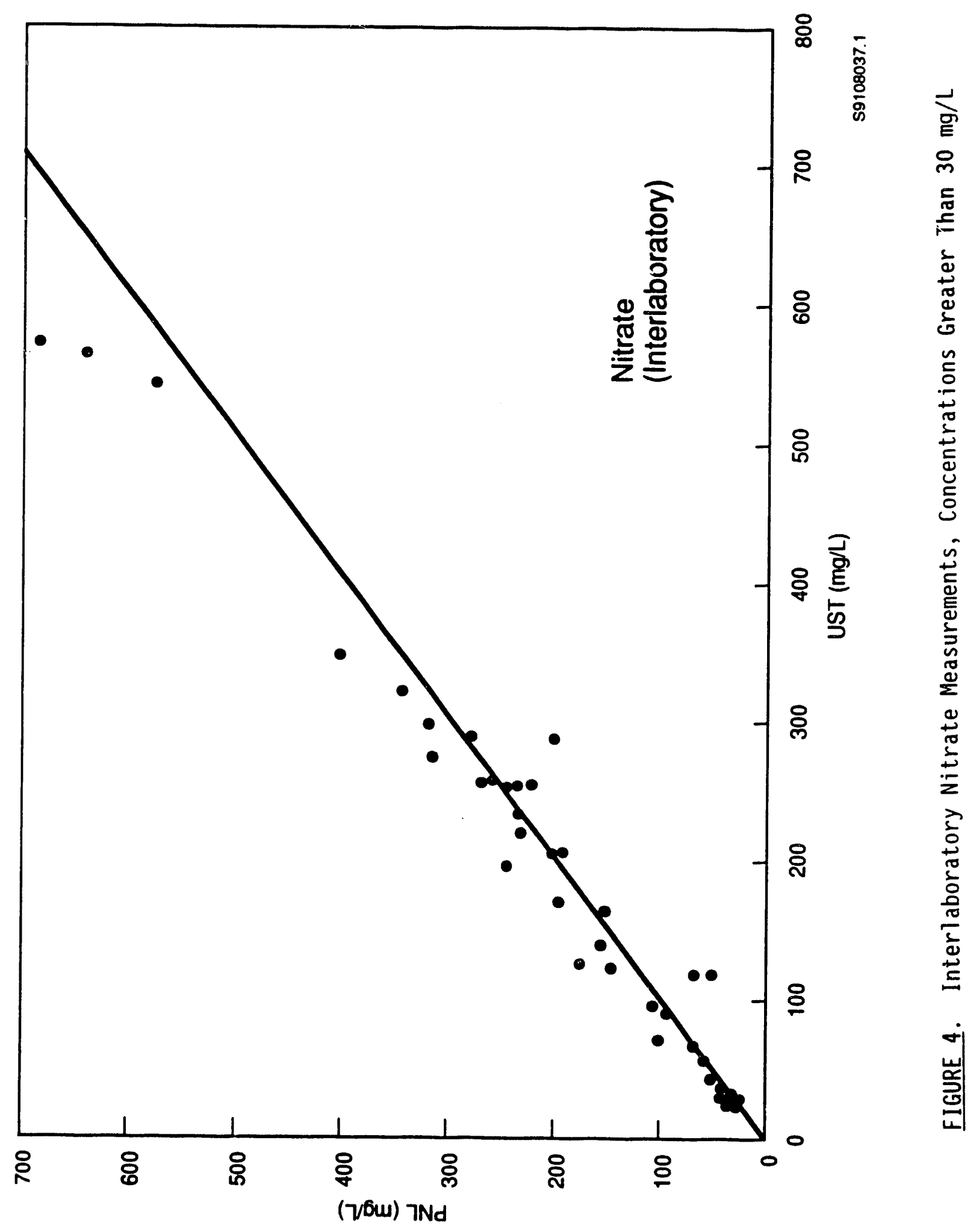




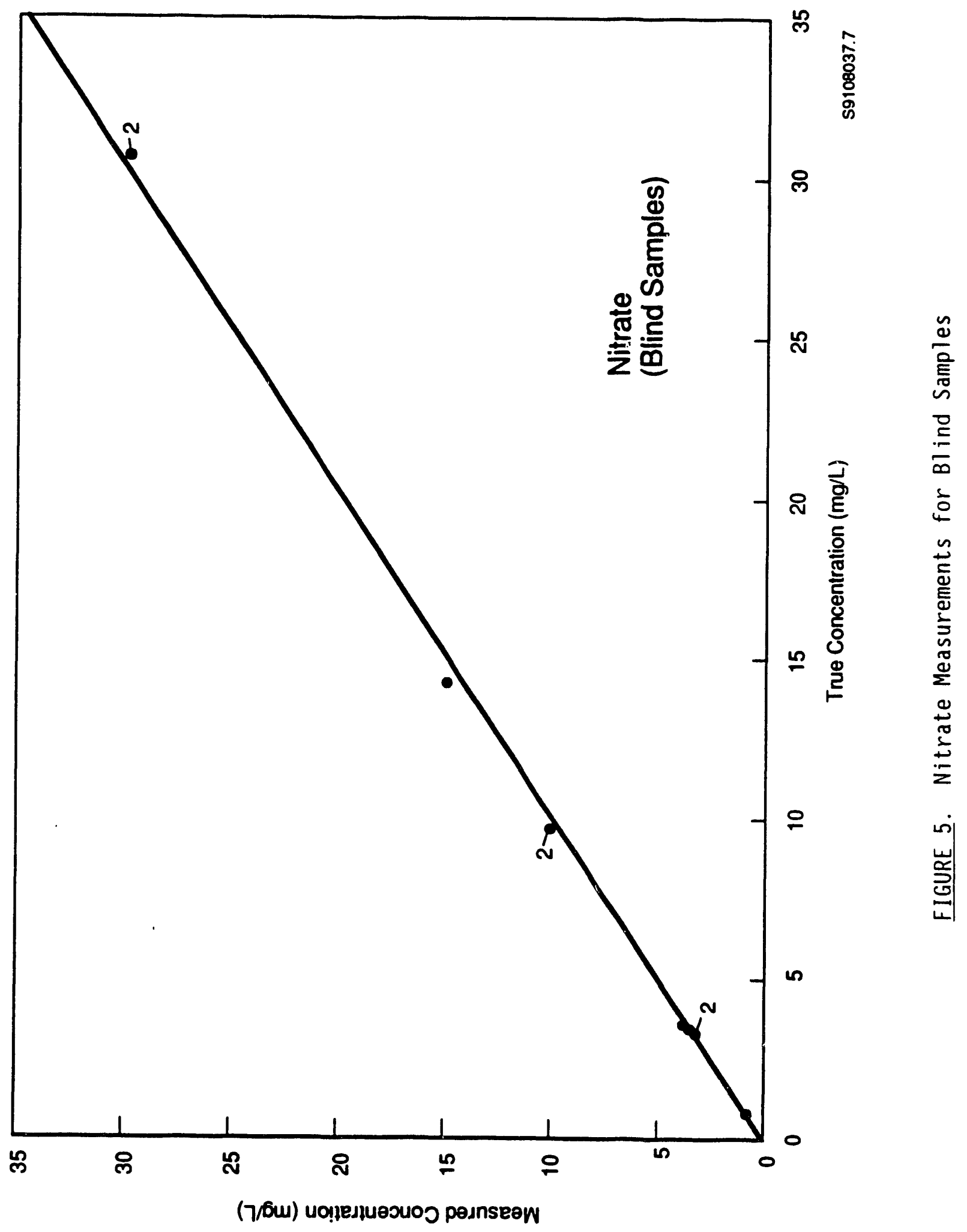


The reslitting estimate of the standard deviation is $0.40 \mathrm{mg} / \mathrm{L}$, which is nearly the same as the estimate of the standard deviation for nitrate interlaboratory comparisons $(0.39 \mathrm{mg} / \mathrm{L})$ in the 0 to $30 \mathrm{mg} / \mathrm{L}$ range, and more than three times greater than that for intralaboratory duplicate measurements $(0.12 \mathrm{mg} / \mathrm{L})$. Two of the blind samples, both having a concentration of $30.5 \mathrm{mg} / \mathrm{L}$, may have been analyzed using dilution before measurement to strictly adhere to the $30.0-\mathrm{mg} / \mathrm{L}$ upper calibration 1imit. By eliminating these samples and recalculating the standard deviation for the remaining eight samples, the result is an estimated standard deviation of $0.41 \mathrm{mg} / \mathrm{L}$. In either case, it is clear that the actual precision of nitrate measurements performed by UST is reflected by the results of interlaboratory, rather than intralaboratory, duplicate comparisons. This conclusion can be confirmed using a variance ratio test (Youden 1963; ASTM 1987). Results of the variance ratio test show that at an alpha-level of 0.05 , the standard deviation calculated from the results of analysis of blind samples (either 0.40 or $0.41 \mathrm{mg} / \mathrm{L}$ based on 10 and 8 samples, respectively) is statistically indistinguishable from the standard deviation calculated from interlaboratory duplicate comparisons and is significantly greater than the standard deviation calculated from intralaboratory duplicates.

Unlike precision, the absolute accuracy of a chemical measurement must be determined using samples of known concentration. APHA (1975) recommends a minimum of 20 measurements of a stable control sample to assess accuracy at any one concentration level and defines accuracy as the difference between the mean measured concentration and the true concentration. In the present case, only 10 sample results (the blind samples) are vailable. These represent a range of concentrations rather than a single-concentration control sample, so accuracy must be expressed as the average deviation over the concentration range. That is, for each sample, the true (known) value is subtracted from the measured value and the differences are averaged. For the 10 samples, the average deviation is $+0.09 \mathrm{mg} / \mathrm{L}$. This is less than one-fourth of the estimated standard deviation and is comparable to the detection limit of the method $(0.1 \mathrm{mg} / \mathrm{L})$, so it must be concluded that there is no evidence of significant bias in the method. Relative deviation for the 10 samples ranged from $-3.6 \%$ to $+6.5 \%$, and the average relative deviation was $+1.5 \%$. 
Analytical recoveries of matrix spikes performed for UST's internal QC have been routinely reported to $\mathrm{PNL}$. This evidence helps to confirm that there is little or no measurement bias from the analytical method or from ground-water sample matrices typical of the Hanford Site. However, spike recoveries must always be interpreted cautiously because results are necessarily calculated by difference, which effectively doubles analytical uncertainty.

According to APHA (1975), an analytical method is considered in control when the results of analysis of a control sample of known concentration indicate an error of less than or equal to plus or minus three standard deviations. These bounding limits are the upper and lower "three-sigma" control limits, respectively. Bounding limits equal to plus or minus two standard deviations are considered to be upper and lower warning limits. When duplicate samples of unknown true concentration are used as control samples, the three-sigma control limits are plus or minus 3.686 standard deviations (ASTM 1987). Thus, using either Equation (3) or Equations (1) and (2), it is possible to monitor continuing analytical performance against historical performance, using the latter to establish performance standards. However, it is also important to use an external criterion against which to judge the acceptability of that historical performance. Toward this end, the EPA has reported reasonable laboratory performance goals, based on the results of an extensive interlaboratory study of precision and accuracy in the measurement of many water quality parameters, including nitrate in the 0 - to $38-\mathrm{mg} / \mathrm{L}$ range (Britton 1989). According to Britton (1989), who used the results of analysis of known samples by a large number of participating laboratories, the standard deviation of the same nitrate method used by both UST and PNL can be calculated for any concentration level up to $38 \mathrm{mg} / \mathrm{L}$ using the following regression formula:

$$
s=0.0652 C+0.0576
$$

where $C$ is the nitrate concentration $(\mathrm{mg} / \mathrm{L})$. The three-sigma control limits based on this regression are included in Figure 2. From Figure 2, it is clear 
that, with the exception of one data point, the nitrate determination is in control and that the precision of measurement meets the level of performance recognized by the EPA.

Upper and lower control limits based on Equations (1) and (2) are also included in Figure 2. Inspection of the figure shows that this method of estimating the standard deviation tends to overstate precision for higher concentrations and to understate precision for low concentrations.

By applying Equations (1) and (2) to narrow concentration ranges within the UST/PNL interlaboratory data, it is possible, though not strictly correct, to compare precision calculated from Equations (1) and (2) to precision calculated from the regression expressed in Equation (4). To do this, the interlaboratory data were grouped into five ranges within a 0 - to $40-\mathrm{mg} / \mathrm{L}$ overall range, and the standard deviation was estimated for each group of data. Then, Equation (4) was used to calculate a standard deviation for the midpoint of each range. For example, the standard deviation based on duplicates having concentrations in the $0-$ to $5-\mathrm{mg} / \mathrm{L}$ range was compared to the result from Equation (4) for $2.5 \mathrm{mg} / \mathrm{L}$. In a few instances, the measured results from duplicate samples overlapped adjacent concentration ranges, so the mean of the two measurements was used to determine the range to which the data were assigned. Table 1 lists the results of these calculations.

TABLE 1. Interlaboratory Analytical Precision for Nitrate Measurements

United States Testing Company/

Pacific Northwest Laboratory

\begin{tabular}{ccc}
$\begin{array}{c}\text { Number } \\
\text { of } \\
\text { Samples }\end{array}$ & $\begin{array}{c}\text { Concentration, } \\
\mathrm{mg} / \mathrm{L} \mathrm{as} \mathrm{NO}_{3}^{-}\end{array}$ & $\begin{array}{r}\text { Standard } \\
\text { Deviation, } \\
\mathrm{mg} / \mathrm{L} \mathrm{as} \mathrm{NO}_{3}^{-}\end{array}$ \\
\hline
\end{tabular}

28

13

5

10

6
0 to 5

$>5$ to 10

$>10$ to 20

$>20$ to 30

$>30$ to 40
0.26

0.31

0.73

1.06

2.13
U.S. Environmental Protection Agency

\begin{tabular}{|c|c|}
\hline $\begin{array}{l}\text { Concentration, } \\
\mathrm{mg} / \mathrm{L} \text { as } \mathrm{NO}_{3}^{-}\end{array}$ & $\begin{array}{l}\text { Standard } \\
\text { Deviation, } \\
\mathrm{mg} / \mathrm{L} \text { as } \mathrm{NO}_{3}^{-}\end{array}$ \\
\hline
\end{tabular}

2.5

0.22

7.5

0.55

15.0

1.04

25.0

1.68

35.0

2.34 
From Table 1, actual interlaboratory performance appears to be slightly more precise than the performance predicted from Equation (4), except for the lowest range ( 0 to $5 \mathrm{mg} / \mathrm{L}$ ). However, applying the variance ratio test (again at an alpha level of 0.05 ) shows that the differences cannot be considered significant, except for the 5 - to $10-\mathrm{mg} / \mathrm{L}$ range, where actual performance is significantly better than that predicted from Equation (4).

From the foregoing, some conclusions regarding the nitrate determination can be reasonably drawn. In the $0-$ to $38-\mathrm{mg} / \mathrm{L}$ range, historical analytical performance from September 1987 to January 1990 for both PNL and UST has been equal to or slightly better than that established by the EPA as representing a large number of laboratories using the same analytical method. Analytical variability calculated from the results of UST intralaboratory (side-by-side) duplicate analysis is not representative of actual performance. The assumption that sampling, handling, and storage procedures are adequate is justified (this is especially strengthened by Figure 1, which shows the results of side-by-side measurements). The interlaboratory comparison data alone are sufficient to establish confidence limits for the nitrate measurements.

Curiously, when Figure 1 is compared to Figure 3 , it is seen that the dilution error has apparently not affected samples at UST that required dilution. We find this to be highly unlikely and note that such results might be more reasonably expected where a single diluted sample is simply measured twice. 


\section{CHROMIUM}

Hexavalent chromium contamination in the unconfined aquifer on the Hanford Site is associated with several liquid waste disposal facilities (Evans et a1. 1989). Ground-water samples for the chromium determination reviewed in their study were filtered and then preserved on collection with nitric acid. Samples were acid digested in the laboratory, and the chromium concentrations were measured using inductively coupled plasma atomic emission spectroscopy according to the method presented by EPA (1982). Although the holding time for these acid-preserved samples is 28 days, duplicate samples submitted to UST were assumed to have been measured side by side. The best obtainable detection limit for the method may be less than $5 \mu \mathrm{g} / \mathrm{L}$, though UST and PNL report concentrations less than 10 and $20 \mu \mathrm{g} / \mathrm{L}$, respectively, as below the detection limit. Instrument response is nearly linear up to at least $10,000 \mu \mathrm{g} / \mathrm{L}$. The highest chromium concentrations measured in ground water from the Hanford Site are far below this, so no sample dilutions are required for analysis in the laboratory.

Intralaboratory and interlaboratory duplicate samples for chromium are currently submitted at the same rate as for nitrate. However, fewer monitoring wells intercept chromium contamination plumes, so the majority of analytical measurements have been reported as below the detection limits. Since December 1986, 31 intralaboratory and 28 interlaboratory duplicate measurements are available for samples where both reported results are above the detection limit. Results from nine blind samples submitted since November 1987 are also available.

Figure 6 represents intralaboratory chromium measurements obtained during side-by-side analysis of duplicate samples submitted to UST. The calculated standard deviation based on Equations (1) and (2) is $8.0 \mu \mathrm{g} / \mathrm{L}$. Figure 7 represents interlaboratory duplicate measurements, and the standard deviation is $11.3 \mu \mathrm{g} / \mathrm{L}$, which is significantly greater than that of data represented in Figure 6 (based on a variance ratio test at an alpha level of 0.05 ). Figure 8 


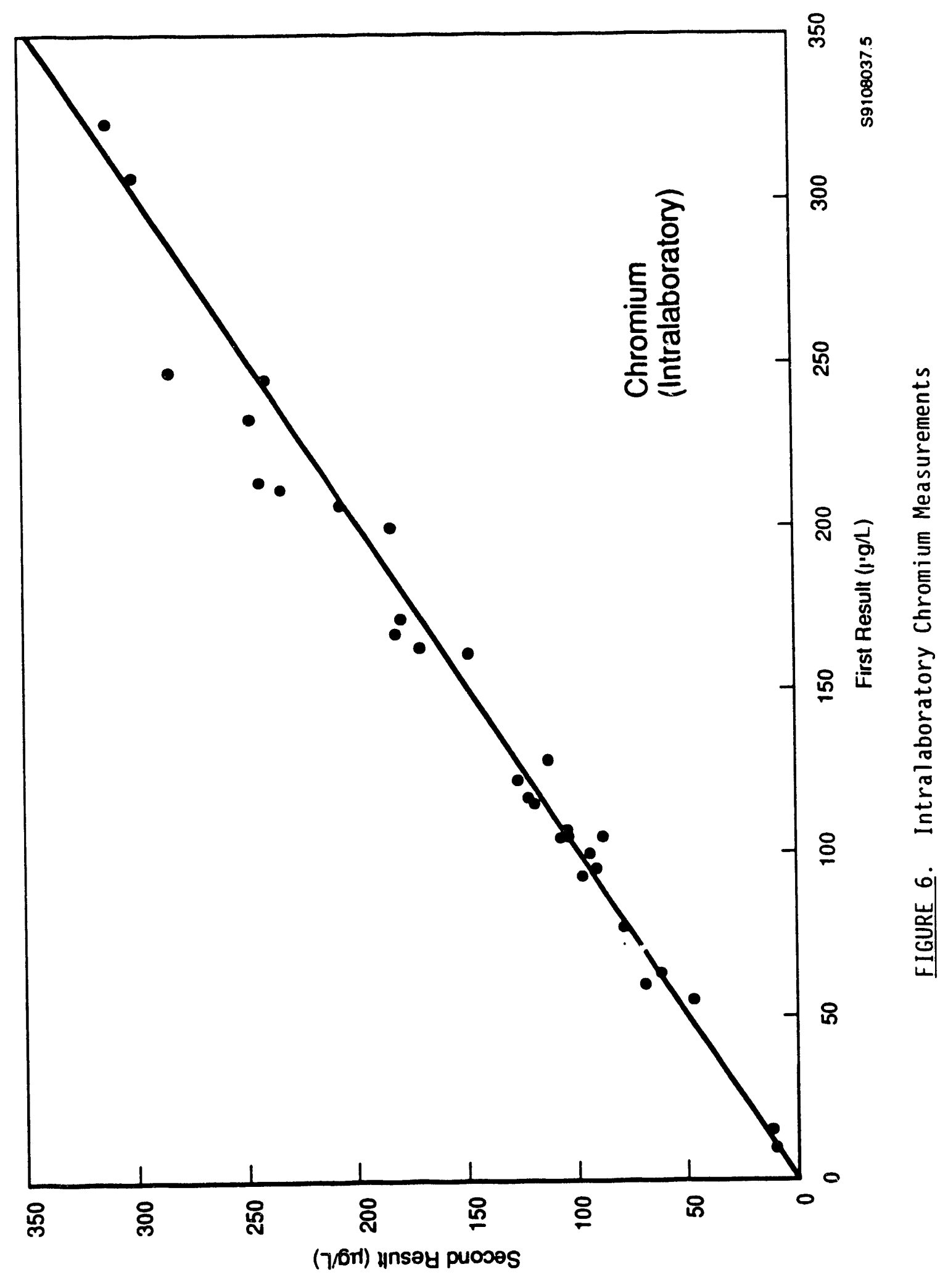




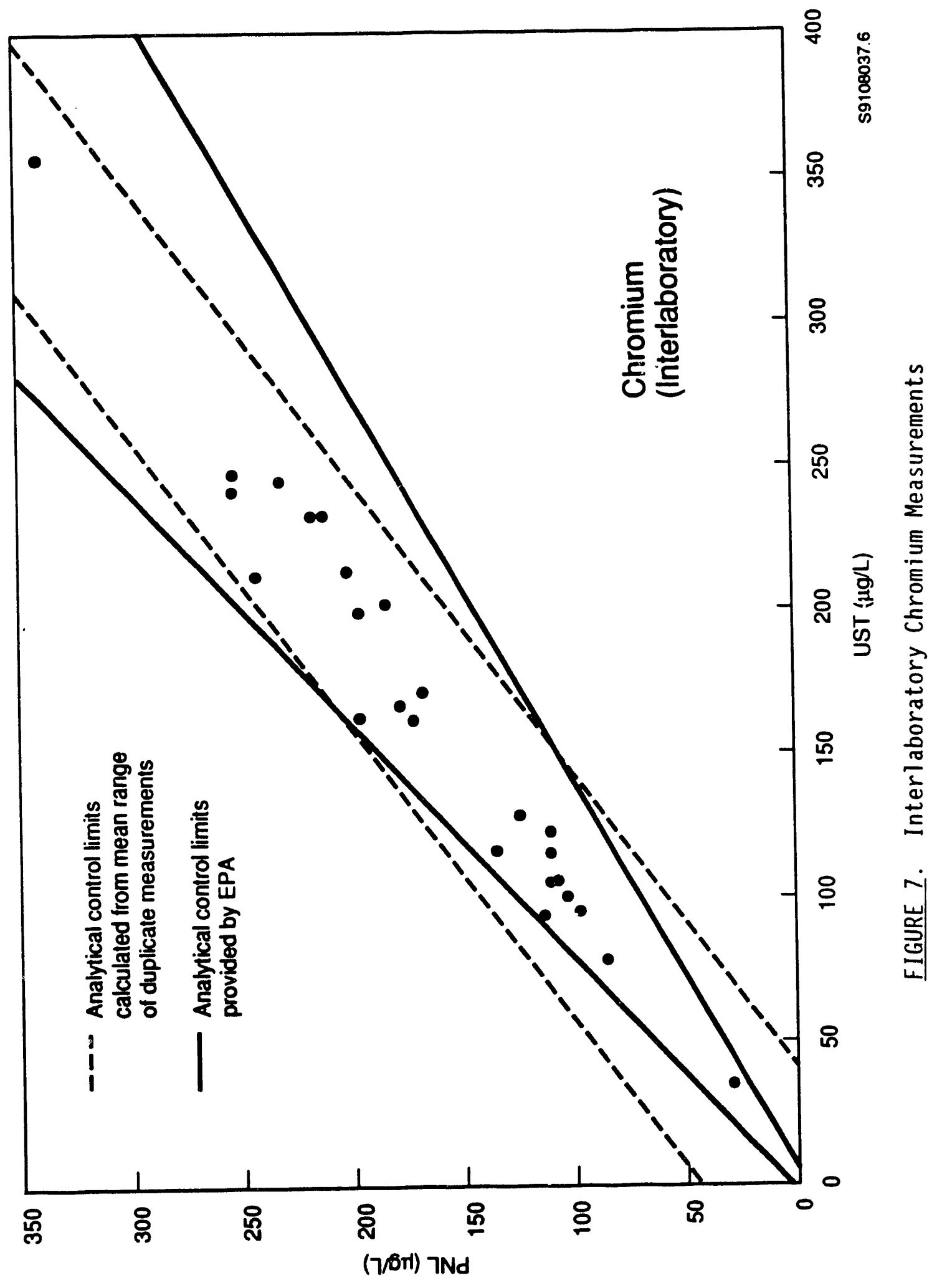




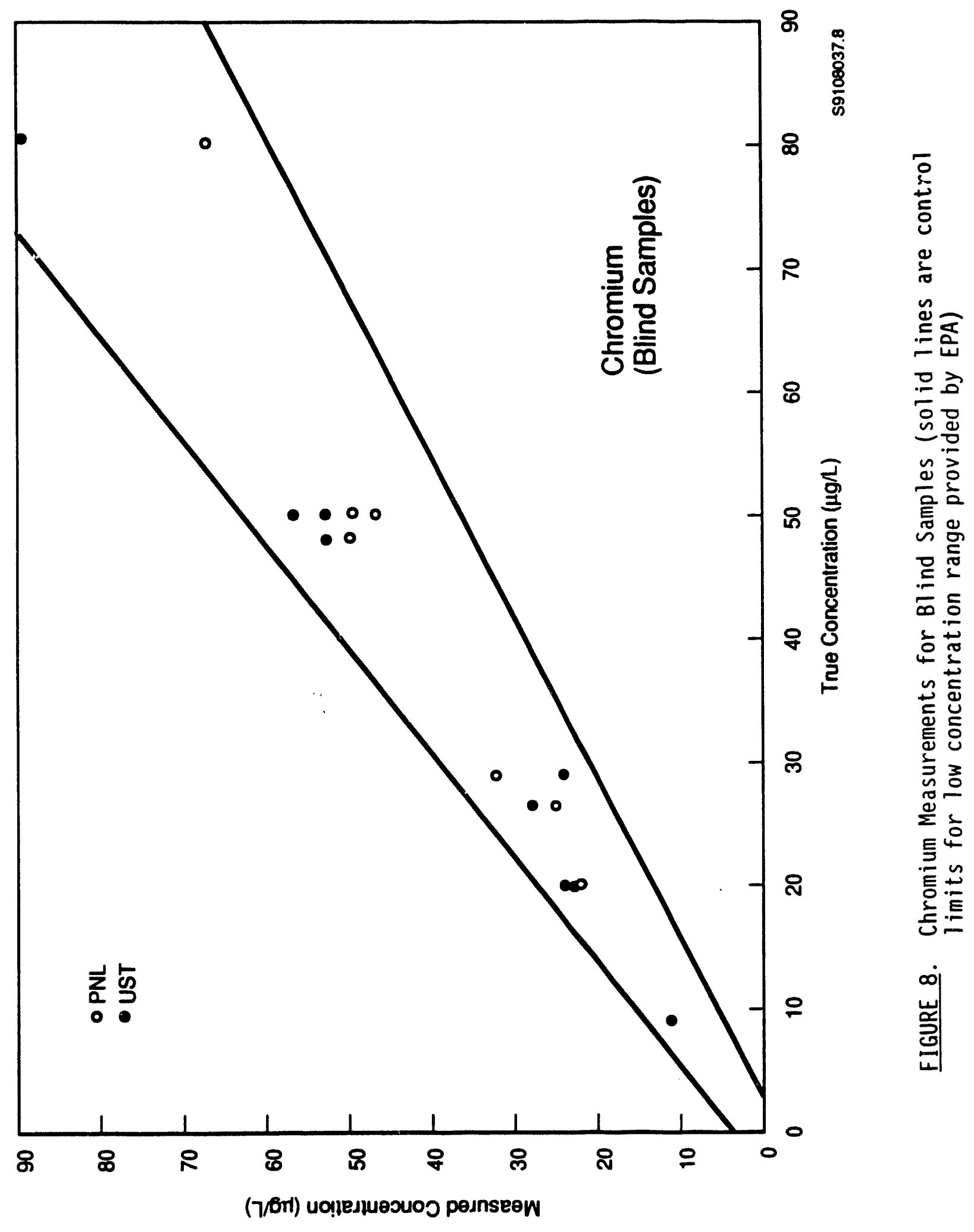


shows the results of analysis of the blind samples, and the calculated standard deviation based on Equation (3) is $5.5 \mu \mathrm{g} / \mathrm{L}$ for the $9-$ to $80-\mu \mathrm{g} / \mathrm{L}$ concentration range.

Britton (1989) provides the following regre,sion formula for interlaboratory precision of the chromium determination for concentrations up to $830 \mu \mathrm{g} / \mathrm{L}$ :

$$
s=0.0671 C+1.106
$$

where $C$ is the chromium concentration $(\mu \mathrm{g} / \mathrm{L})$.

Control limits based on Equations (1) and (2) are included in Figure 7. Figure 8 includes control limits based on Equation (5). From these figures, chromium measurements are within EPA precision expectations. The calculated mean relative recovery for the blind samples is $109 \%$ for UST and $97 \%$ for PNL. 


\section{SODIUM}

Sodium, which is not considered a contaminant, is a universal constituent in ground water beneath the Hanford Site. Natural sodium concentrations in the unconfined aquifer are generally low, on the order of a very few milligrams per liter. Nevertheless, sodium is associated with certain waste plumes at Hanford and is routinely determined in samples collected from monitoring wells. Sample preparation and analysis is by the incuctively coupled plasma method. The sodium determination is included here because it is useful to illustrate the method's performance at concentrations much greater than those of contaminant metals, such as chromium.

Sodium up to $40 \mathrm{mg} / \mathrm{L}$ may be measured without sample dilution. From January 1987 to May 1990, duplicate sample sets analyzed by UST and PNL showed concentrations ranging from less than 2 to nearly $800 \mathrm{mg} / \mathrm{L}$. Blind samples are not submitted for sodium analysis. Analytical performance expectations in the range 0 to $95 \mathrm{mg} / \mathrm{L}$ (Britton 1989) are taken from the regression equation:

$$
s=0.0396 C+0.1515
$$

where $C$ is the sodium concentration $(\mathrm{mg} / \mathrm{L})$.

Figure 9 illustrates the results of interlaboratory duplicate analyses for sodium. Within the concentration range represented by Equation (6), all but two results are within the three-sigma control limit included in the tigure, though many of the results are marginal.

Figure 10 iliustrates interlaboratory and intralaboratory performance compared to EPA expectacions. In the figure, data are grouped into six concentration ranges, where the relative standard deviations [the result from Eauations (1) and (2) normalized to the mid-point concentration] are plotted against midpoint concentration. A logarithmic abscissa is used for convenience. The EPA expectations from Equation (6) are 37 so plotted. From the figure, it is apparent that UST intralaboratory duplicate analyses appear 
somewhat more precise than EPA expectations, and that the UST/PNL results are less precise. This latter is quite obvious for samples that required dilution (i.e., more than $40 \mathrm{mg} / \mathrm{L}$ ). 


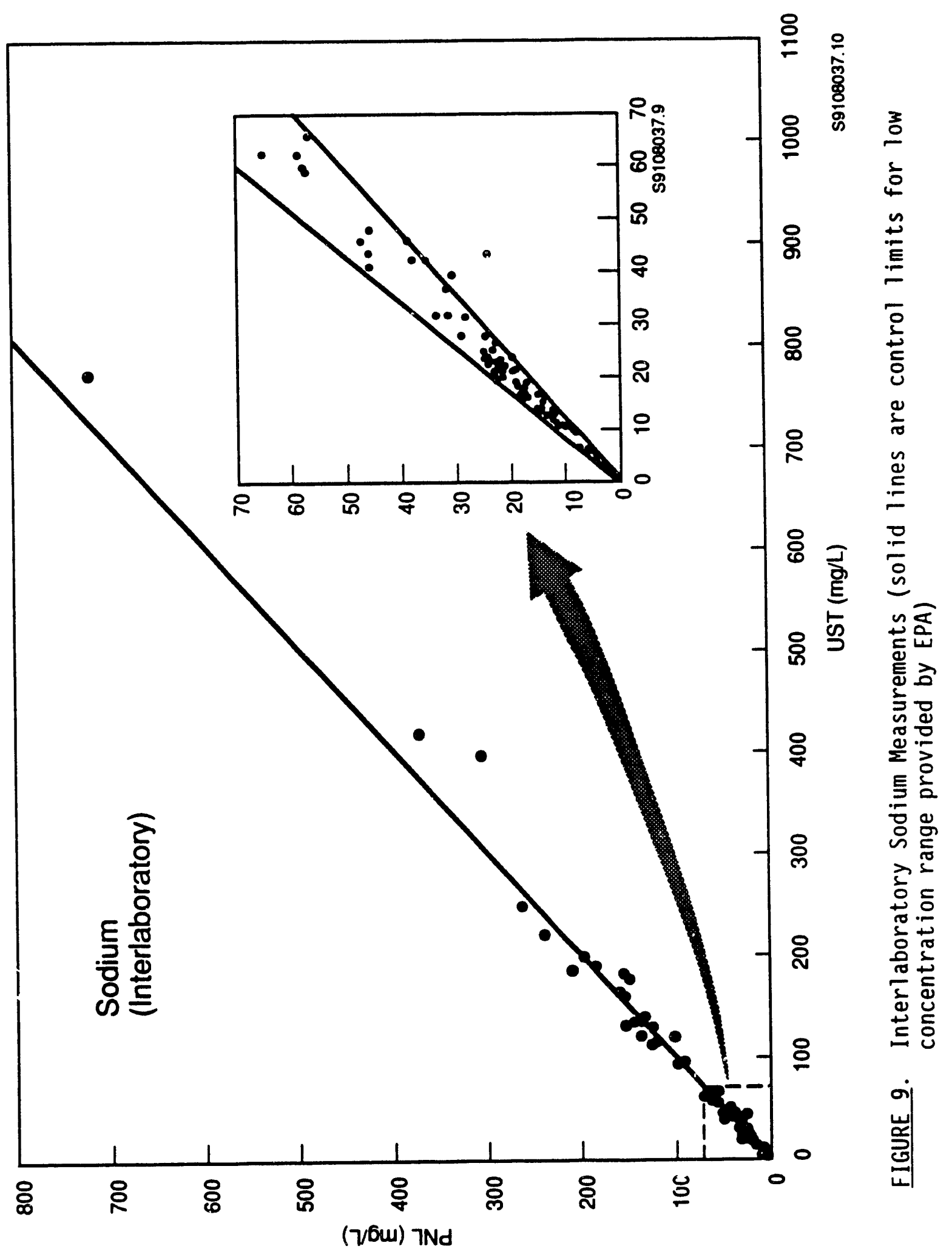




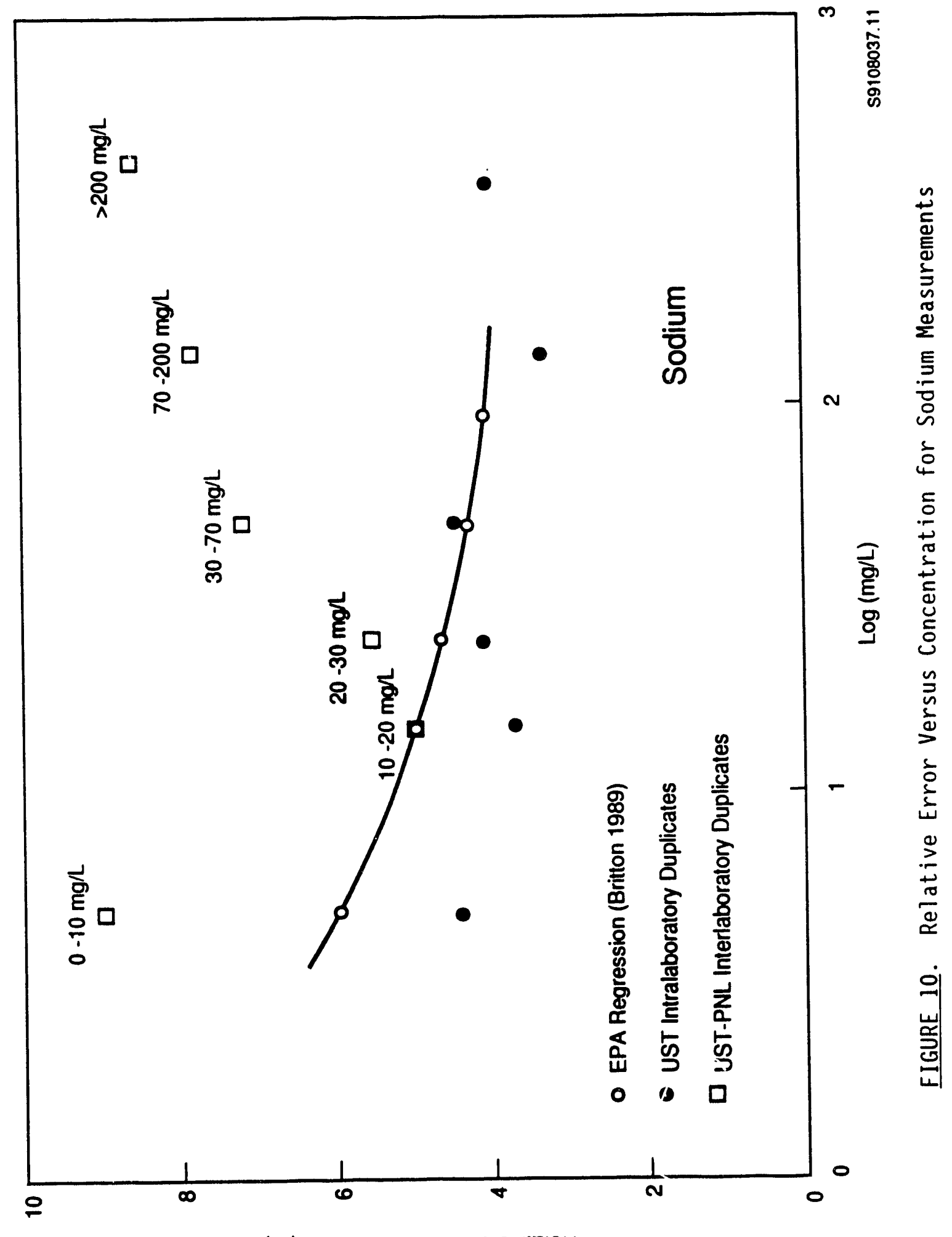

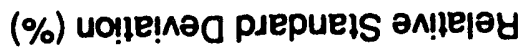




\section{FLUORIDE}

Fluoride is routinely measured in ground-water samples from the Hanford Site. Analysis is generally performed using ion chromatography, and Britton (1989) has provided the following regression formula for calculating standard deviations for concentrations up to $3.7 \mathrm{mg} / \mathrm{L}$ :

$$
s=0.0301 C+0.0214
$$

where $C$ is the fluoride concentration $(\mathrm{mg} / \mathrm{L})$.

From May 1987 to May 1990, 33 duplicate samples having concentrations in excess of the $0.5-\mathrm{mg} / \mathrm{L}$ UST detection limit were analyzed by both UST and PNL. Figure 11 illustrates the results of this interlaboratory comparison, and it is clear from the figure that many of the measurements are not within EPA expectations for precision. Figure 12 shows the UST intralaboratory duplicate measurements for the same samples shown in Figure 11. The difference between Figures 11 and 12 is striking. Figure 13 shows the results of analysis of blind samples analyzed for fluoride by UST and PNL. The scatter of data points in Figure 13 resembles that of Figure 12 rather than that of Figure 11. From Figures 11 and 13, it is obvious that the analytical method used by UST and PNL is not adequate to meet EPA expectations of accuracy and precision. 


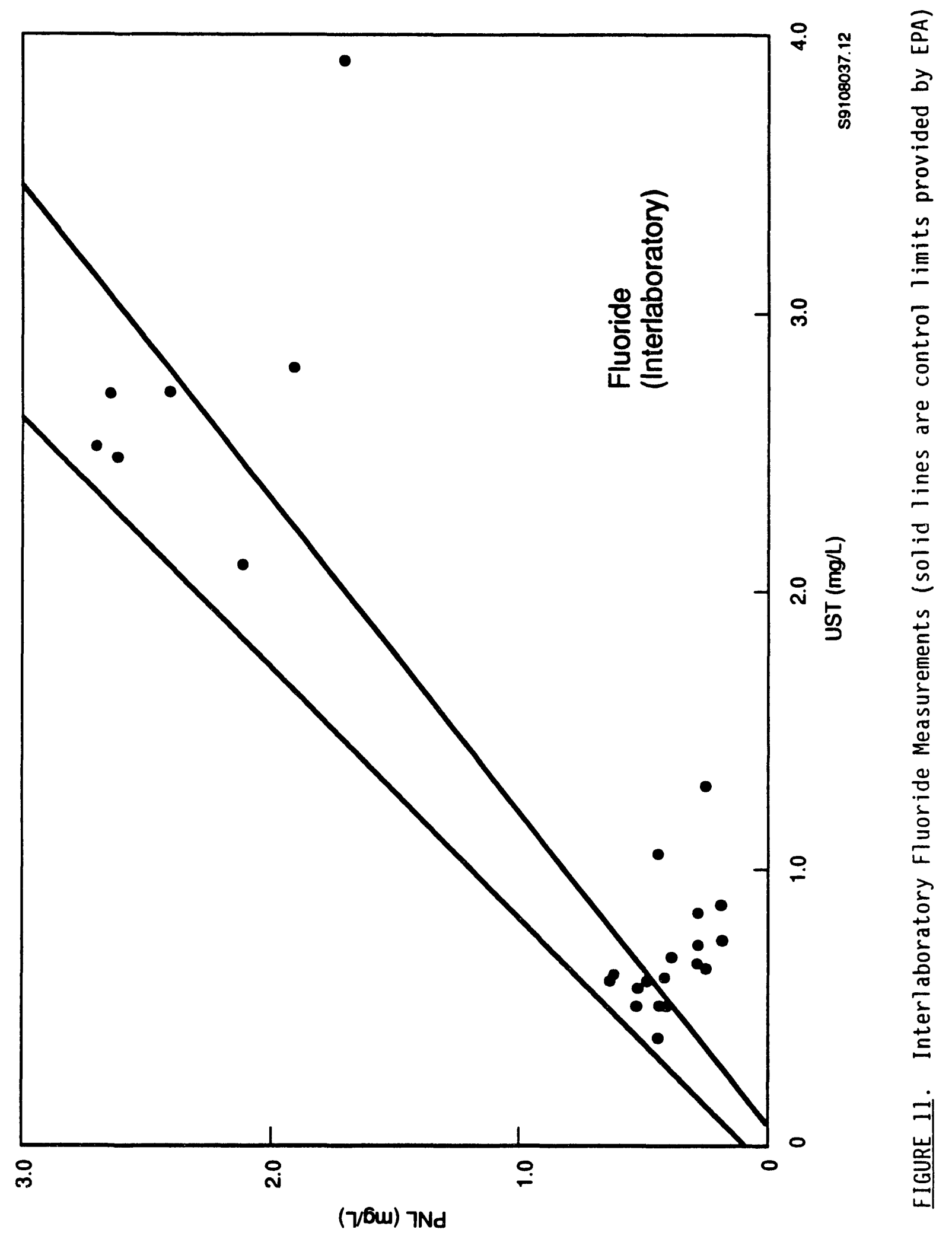




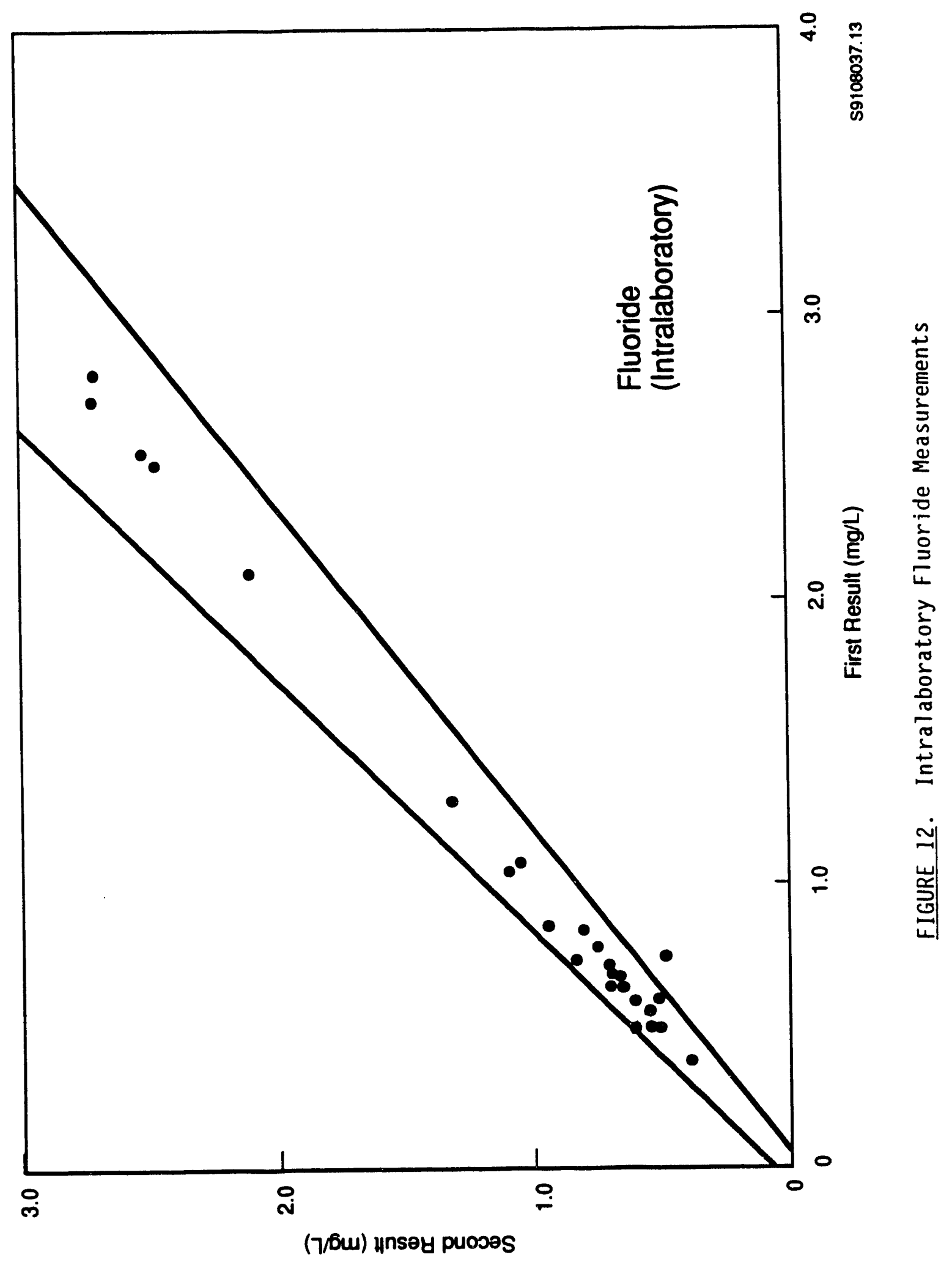




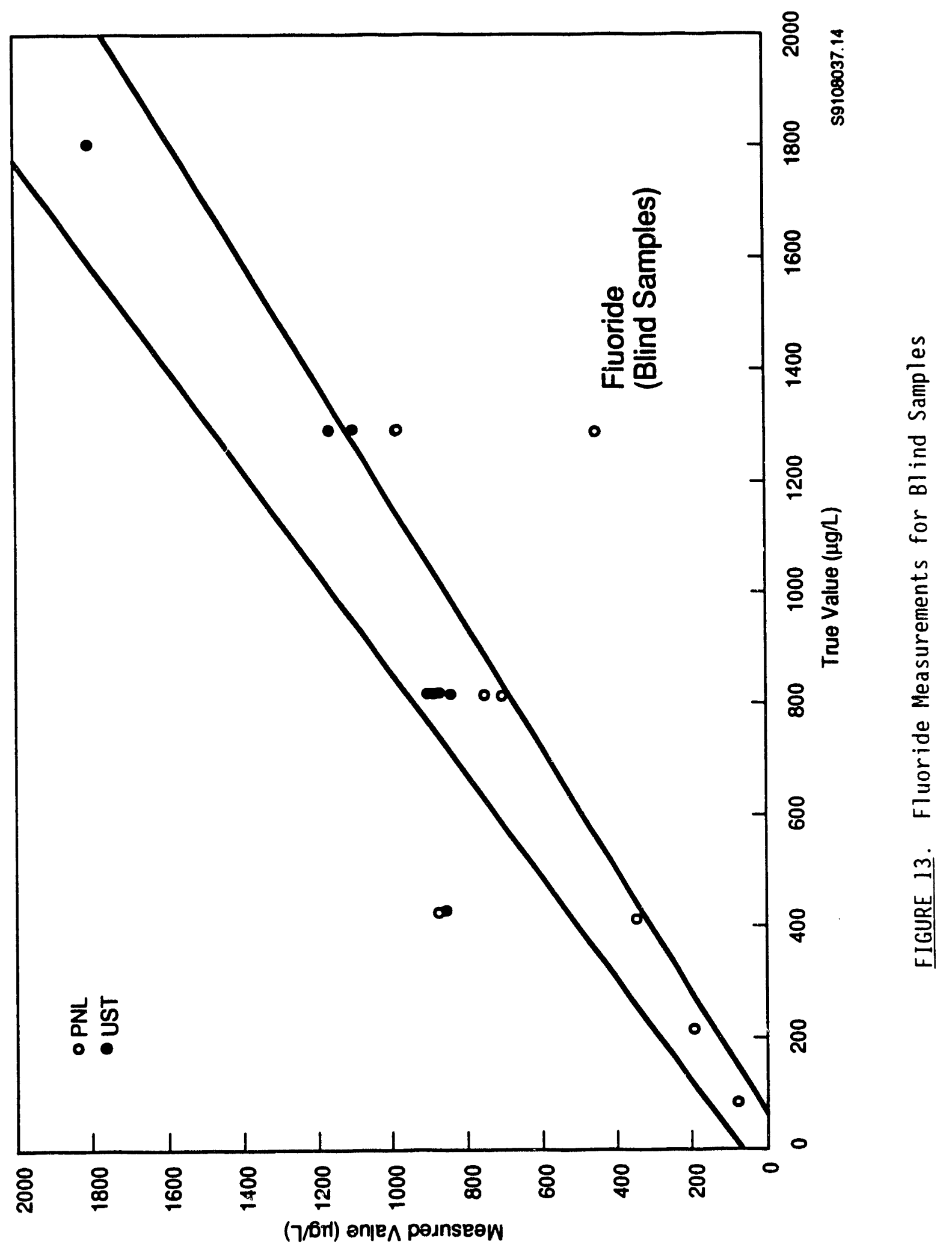




\section{CARBON TETRACHLORIDE}

Carbon tetrachloride, a solvent used in past processing operations at the Hanford Site, has been identified as a ground-water contaminant and is routinely determined in samples collected from selected monitoring wells. From July 1987 to May 1990, 15 samples have shown this solvent to be in excess of the detection limit (generally recognized as $5 \mu \mathrm{g} / \mathrm{L}$ ), and 8 have been analyzed by both UST and PNL. Most of these samples showed concentrations in the range from approximately 100 to nearly $1000 \mu \mathrm{g} / \mathrm{L}$. The EPA provides a regression for estimating the standard deviation only up to a concentration of $97 \mu \mathrm{g} / \mathrm{L}$.

Blind samples have been routinely submitted to both PNL and UST, but the sample concentrations were within the limits of the EPA regression formula range. The results of blind sample analysis were all within the three-sigma control limits based on EPA expectations.

Although demonstrated analytical performance for concentrations less than $100 \mu \mathrm{g} / \mathrm{L}$ cannot be reasonably extrapolated to $1000 \mu \mathrm{g} / \mathrm{L}$, it is still possible to compare intralaboratory and interlaboratory performance. Figure $14 \mathrm{illus-}$ trates the results of duplicate analyses within UST and between UST and PNL. Because of the paucity of data, these can be conveniently combined in the same figure. From Figure 14, the contrast in the level of precision between intralaboratory and interlaboratory precision is apparent. Further, it is obvious that submittal of blind samples should be weighted toward higher sample concentration. 


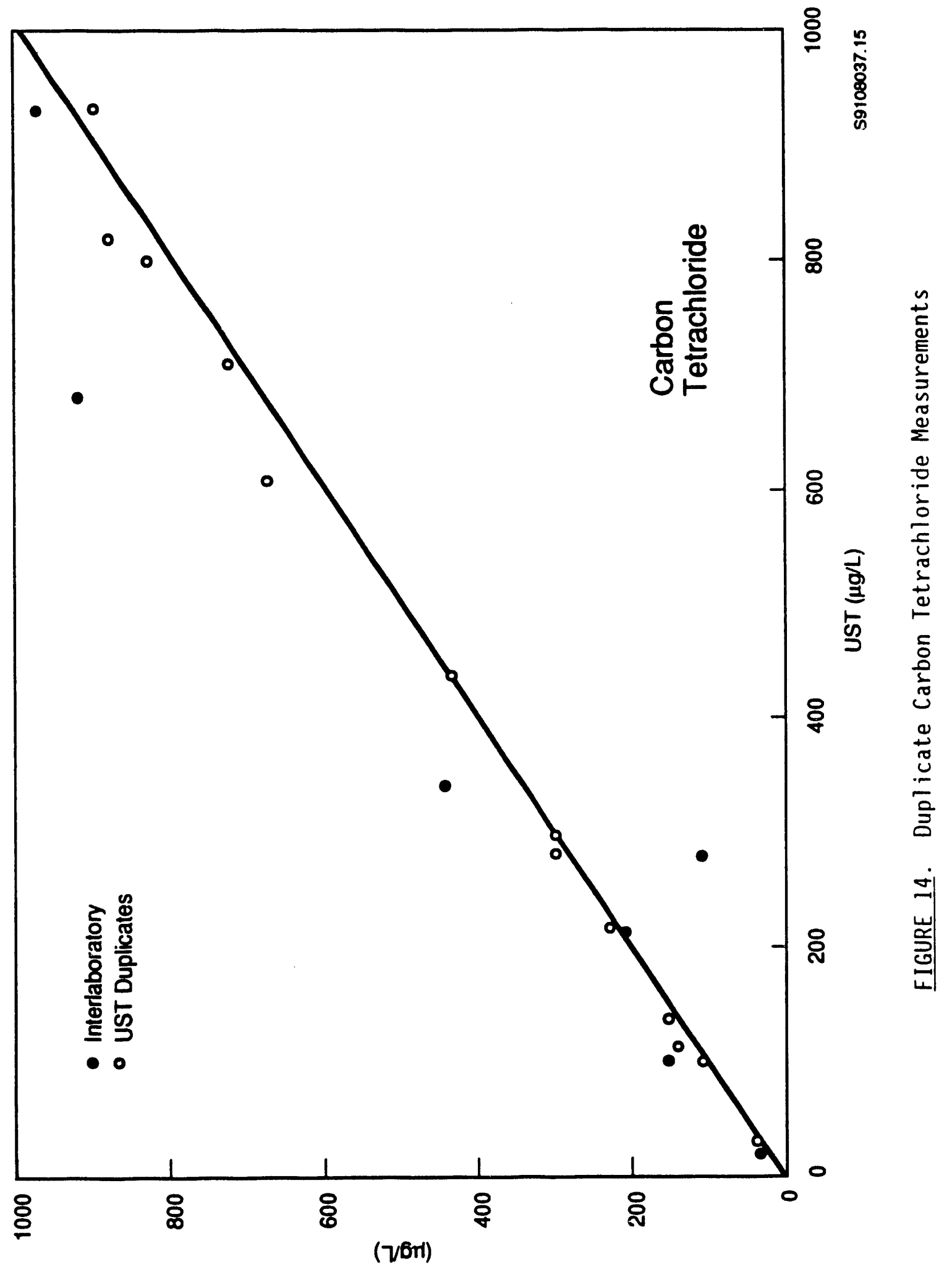




\section{TRITIUM}

Tritium is associated with process wastes at the Hanford Site, and elevated concentrations are commonly found in the unconfined aquifer. From July 1988. to May 1990, reported concentrations of tritium in ground-water samples ranged from less than 16 to nearly $5,000,000 \mathrm{pCi} / \mathrm{L}$. Tritium is measured by direct radiometric counting. The EPA does not provide generic quality control limits as it does for the constituent species discussed above. During the stated time period, 17 samples with tritium concentrations greater than $1000 \mathrm{pCi} / \mathrm{L}$ were submitted to both UST and PNL. Figure 15 shows the results of the interlaboratory measurements. Concentrations ranged over three orders of magnitude, but the relative error, as seen in Figure 15, appeared to be nearly independent of concentration. Equation (1) was modified so that the result represented the mean relative difference between UST- and PNL-reported concentrations. For each pair of measurements, the absolute value of the difference between the measurements was divided by the reported UST value. The mean of these results was used in place of $R$ in Equation (2), and the $5.9 \%$ result from Equation (2), is taken as the estimate of the relative standard deviation of the analytical method.

Duplicate determinations in this series of measurements were reported by UST. An estimate of error for each sample, based on counting statistics, was reported by PNL. The duplicate UST measurements, as well as the analytical uncertainties reported by PNL, indicated precision much greater than the $5.9 \%$ relative standard deviation calculated from Equation (2). 


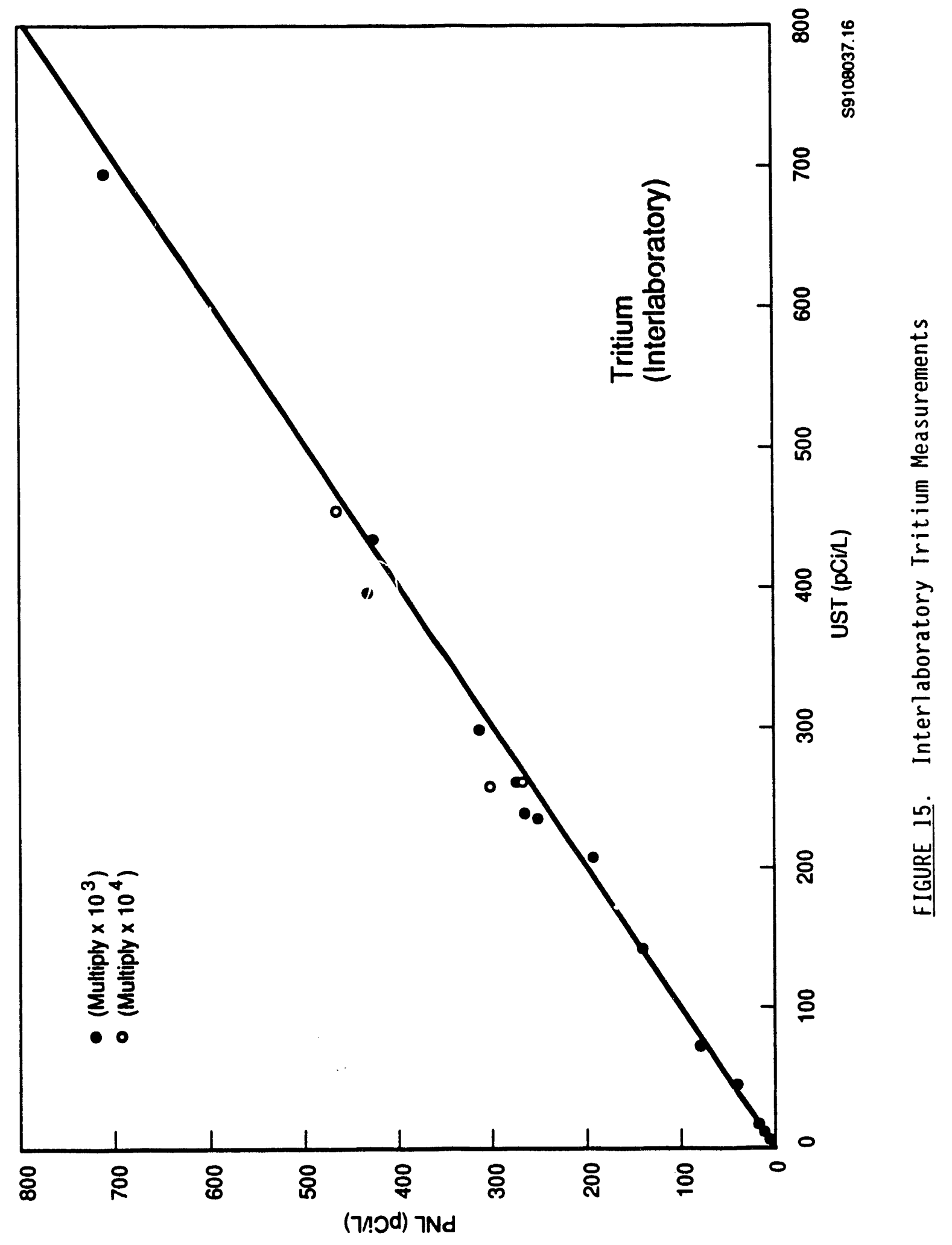


Ammonium, trichloroethylene, and cyanide were also considered in this study. Each of these is a contaminant of concern at the Hanford Site. Ammonium represents measurements performed using ion-selective electrode technology. Trichloroethylene, like carbon tetrachloride, is measured using gas chromatography but at much lower concentrations. Cyanide was chosen because it is measured using visible-range spectrophotometry. Too few data for these determinations are available to draw meaningful statistical conclusions based on interlaboratory comparisons. However, numerous blind samples have been submitted and analyzed within the time frame discussed above, and EPA (Britton 1989) has presented generic quality control limits. Figures 16 through 18 illustrate the results of blind sample analysis for each of these constituents, and each figure includes the three-sigma control limits. From the figures, it is seen that laboratory performance is generally within the control limits for these measurements. 


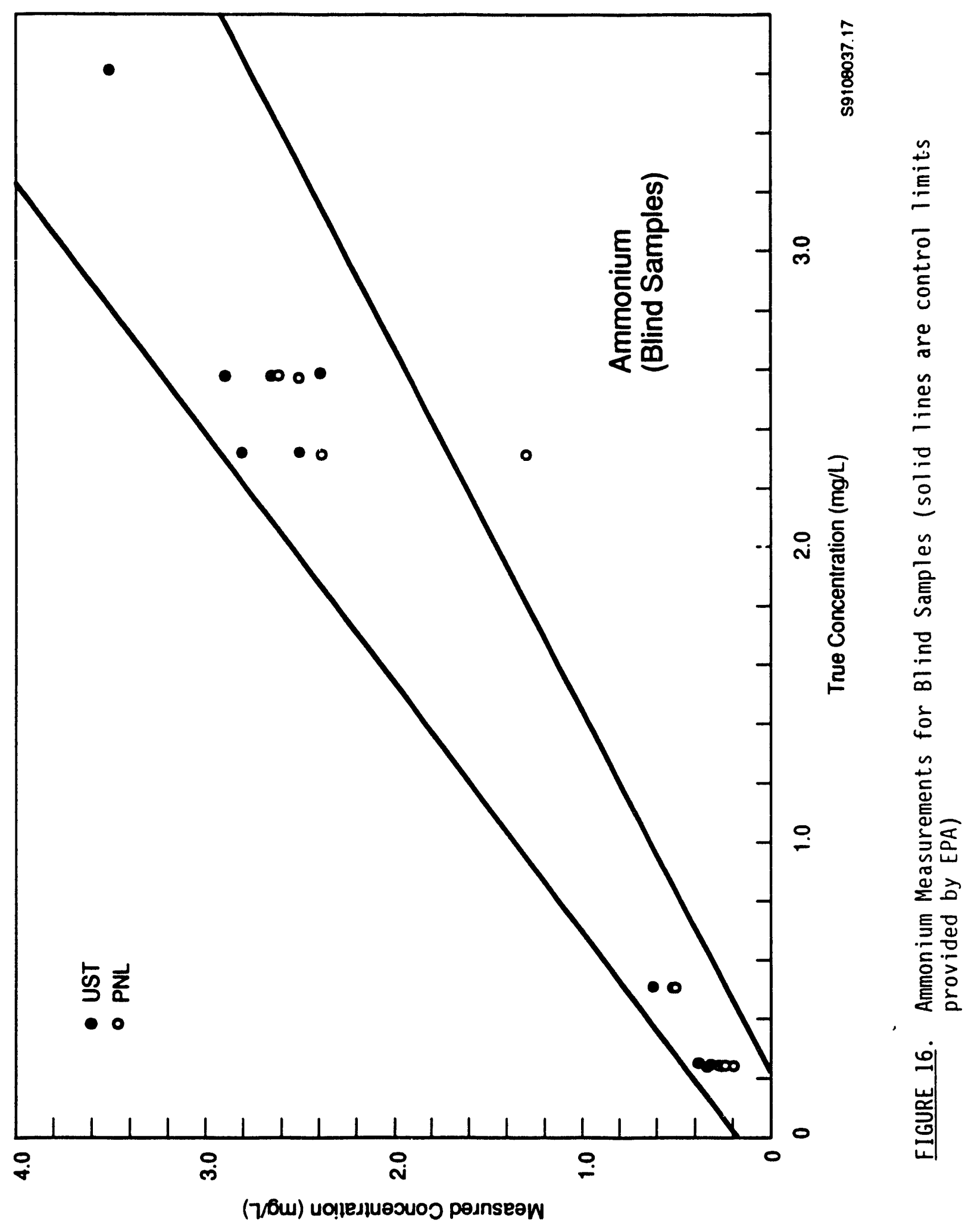




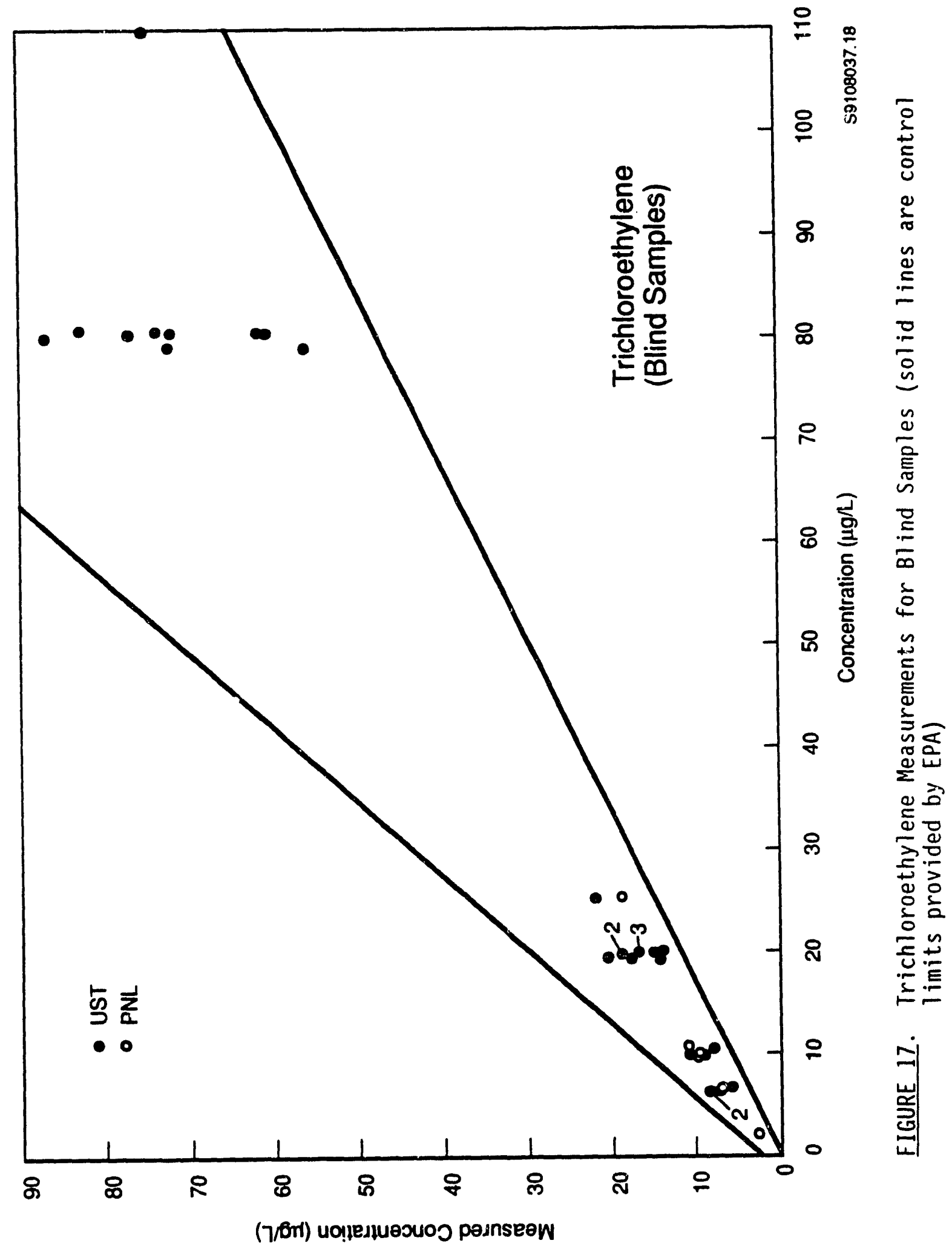




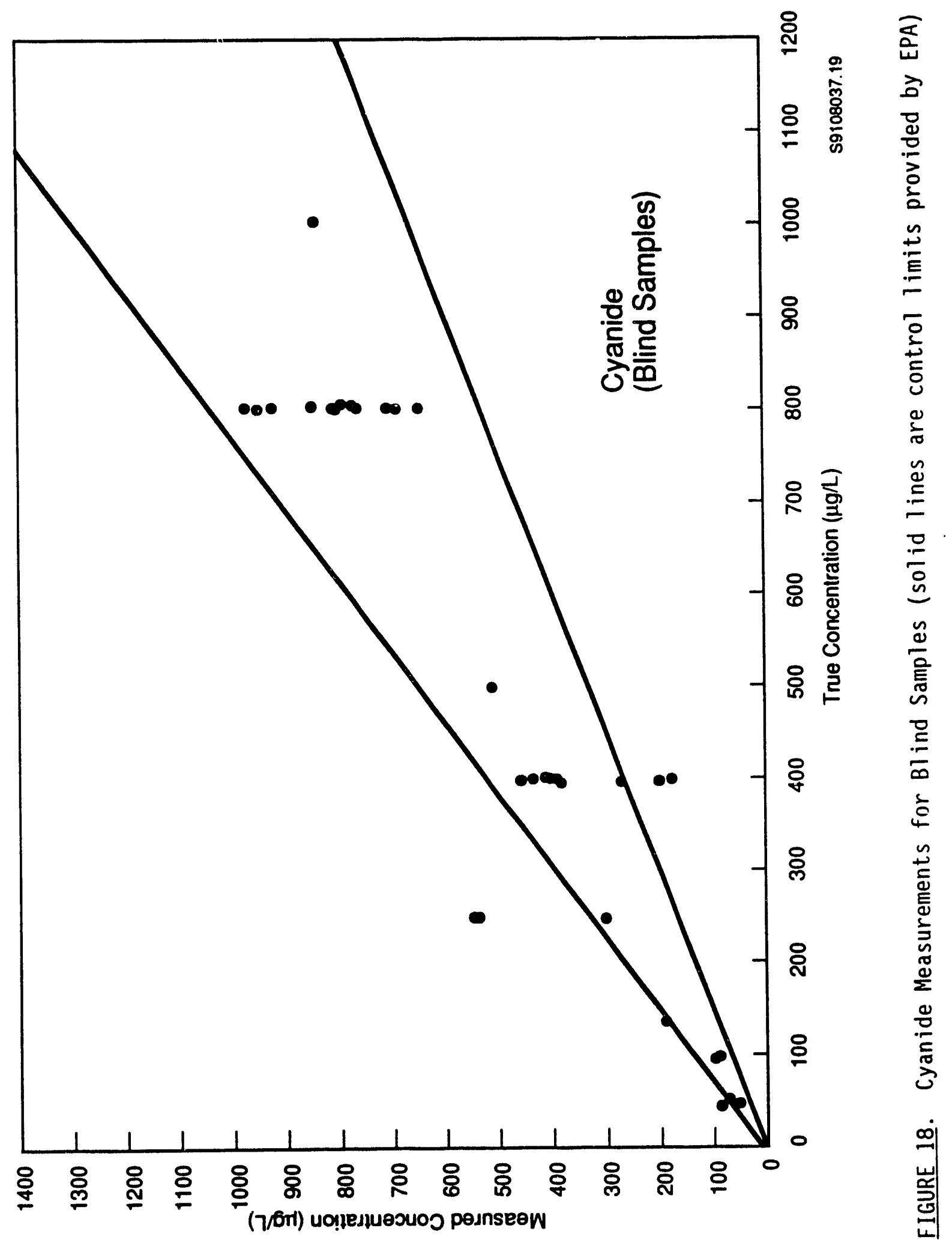




\section{DISCUSSION AND RECOMMENDATIONS}

In the foregoing sections, we have focused on the difference between intralaboratory and interlaboratory precision in the chemical analysis of ground-water samples. It has been pointed out that interlaboratory analysis of duplicate samples takes into account many real analytical variables that are masked by intralaboratory analysis. The data presented show that the precision of measurement of blind samples is generally close to the analytical precision calculated from interlaboratory comparisons and less than the precision calculated from intralaboratory duplicates.

The absolute accuracy of a chemical measurement is always a concern. Blind samples are useful for determining both the precision and accuracy of latoratory measurements. However, it is important to realize that problems with accuracy caused by random contamination, reagent contamination, calibration problems (e.g., inaccurate calibration standards), or sample collection problems, will, with rare exception, ultimately show up as poor interlaboratory precision, or in some unusual cases as distinct interlaboratory bias (i.e., one laboratory is systematically reporting numbers that are significantly higher than those from the other laboratory).

Analytical accuracy for individual samples can be affected by sample matrix, but matrix errors cannot be detected through duplicate analysis. Such errors can be detected using the method of additions (i.e., a spike). The use of spikes is an important facet of internal quality control, but it is not appropriate for an external quality control program for two reasons. First, good laboratory practice dictates that the spike concentration be chosen according to the results of initial analysis. That is, an ideal spike should be approximately equal in concentration to the analyte concentration in the unspiked sample. Both the sample and the spiked sample should also be measured several times to maximize the precision of the results (the analyst will not know to do this for "blind" or "field" spikes). Second, the main value of the method of additions is to correct the analytical result, before it is reported, in the event that significant matrix bias is detected. Routine 
spiking of Hanford Site ground-water samples has shown that matrix bias is not significant with the analytical methods used.

In view of the above, for common analytes (e.g., nitrate, chromium, sodium), there is little technical justification for an external quality control program other than the use of interlaboratory comparisons. For uncommon analytes (e.g., trichloroethylene, cyanide, ammonium), interlaboratory duplicate sample submission should be largely reserved for samples collected from monitoring wells known to be contaminated by such analytes, and these results can be augmented through the use of blind samples. As long as the results of duplicate or blind sample analysis meet EPA expectations, the assumption that sample collection, preservation, handling, and analysis are adequate can be reasonabiy taken as correct.

Submittal of replicate samples for intralaboratory analysis should be reserved for studies where it is suspected that contamination or sampling difficulties (e.g., well purging) may be causing actual differences in analyte concentration between replicates (replicates are normally assumed to be identical in composition). Similarly, there is no reason for routine submittal of blanks, except for analytes that have significant environmental impact at or near analytical detection limits.

In reviewing the analytical data, most measurements were found to be within control limits as defined by APHA (1975) and quantified by EPA (Britton 1989). (The fluoride determination is the most obvious exception.) Conclusions were based solely on interlaboratory data and were corroborated by blind sample analysis, except for certain uncommon contaminants where blind data alone were available in sufficient quantity to allow judgment or where EPA control limits are either absent (tritium) or represent an inappropriate concentration range (e.g., sodium, carbon tetrachioride).

Our purpose in conducting this review was to determine whether a quality control program less extensive than PNL's current program could be designed without sacrificing the fundamental technical purposes of external quality control. We conclude that interlaboratory comparison data, supplemented when 
necessary by blind samples, are useful. Intralaboratory duplicate analysis and submittal of blank samples are not useful except in restricted circumstances.

For wells monitored under the Ground Water Surveillance Project, we offer the following specific 'recommendations to reduce sampling, handling, and analytical costs associated with the external QC program:

1. Eliminate the routine collection of $Q C$ samples other than field duplicates, and submit one of the duplicates to the primary laboratory and the other to the referee laboratory. Maintain the present rate of duplicate sample collection; i.e., one well sampled in duplicate per 20 wells sampled.

2. Use "three-sigma control limits" as acceptance criteria for the results of duplicate analytical measurements. That is, the two measurements may differ by 3.686 standard deviations. The standard deviation for each measurement may be estimated from the mean of the reported results and the appropriate regression formula as presented by Britton (1989).

3. Eliminate the routine preparation and submittal of blind standard samples (also known as "performance evaluation standards").

4. Where the results of duplicate measurements do not meet the acceptance criteria, use timely resampling and interlaboratory analys is to resolve discrepancies.

5. Reserve the use of transfer blanks, transport blanks, field blanks, laboratory blanks, intralaboratory duplicates, bottle blanks, and blind standard samples for those instances where resampling does not resolve discrepancies.

Applying these recommendations will reduce the cost of the external QC program. This is especially true for blind standard samples, the preparation of which is extremely labor intensive. Nevertheless, the technical value of the QC program is not compromised. As has been demonstrated in this report, interlaboratory duplicate analysis is sufficient to establish or confirm laboratory performance as well as the adequacy of field procedures and sample handling. This approach is reflected in recommendations 1 through 3 . In the event that laboratory performance does not meet expectations or field methods fail, recommendations 4 and 5 provide the tools needed to detect and correct problems. 
Determining the optimum rate of quality control sample submittal is more difficult than determining the kinds of $Q C$ samples to be submitted. The number of samples that must be submitted for an external quality control program is controlled by the degree of resolution needed for establishing initial confidence limits and for monitoring change. The resolution that is needed is, in turn, controlled by the use to which this knowledge is put. It can be reasonably argued that any periodic, independent assessment of laboratory performance is of little use unless the results of that assessment are used as feedback to the laboratory to correct shortcomings (when necessary) or are reported to and used by technical staff for interpreting geochemical data. Until such uses for the quality control data are addressed and established, there is little reason to have a quality control program that is more extensive than the programs used for quarterly recertification of medical or drinking-water laboratories. 


\section{REFERENCES}

APHA. 1975. "Precision, Accuracy, and Correctness of Analyses." In Standard Methods for the Examination of Water aild Wastewater, 14th Ed., pp. 20-38. Prepared and published jointly by American Public Health Association, American Water Works Association, and Water Pollution Control Federation, Washington, D.C.

ASTM. 1987. D 4210-83, "Standard Practice for Intralaboratory Quality Control Procedures and a Discussion on Reporting Low-Level Data." In 1987 Annual Book of ASTM Standards, Section 11, Water and Environmental Technology, Vol. 11.01 Water, pp. 9-18. American Society for Testing and Materials, Philadelphia.

Britton, P. W. 1989. Table of Statistics from EPA Water Pollution (WP) Performance Evaluation Studies. U.S. Environmental Protection Agency, Washington, D.C.

Evans, J. C., R. W. Bryce, and D. R. Sherwood. 1989. Hanford Site GroundWater Monitoring for January Through June 1988. PNL-6886, Pacific Northwest Laboratory, Richland, Washington.

U.S. Environmental Protection Agency (EPA). 1982. Test Methods for Evaluating Solid Waste: Physical/Chemical Methods. 2nd ed. SW-846, Office of Solid Waste and Emergency Response, Washington, D.C.

U.S. Environmental Protection Agency (EPA). 1984. Test Method for Determination of Inorgani- Anions in Water by Ion Chromatography. EPA-600/484-017, Environmental Monitoring and Support Laboratory, Cincinnati.

Youden, W. J. 1963. "Statistics in Chemical Analysis." In Handbook of Analytical Chemistry, ed. L. Meites, pp. 14-1 - 14-10. McGraw-Hill Book Company, New York. 


\section{DISTRIBUTION}

No. of

Copies

OFFSITE

2 DOE Office of Scientific and Technical Information

\section{ONSITE}

1 DOE Field Office, Richland

R. D. Hildebrand

A5-55

25 Pacific Northwest Laboratory

R. W. Bryce

K6-96

P. G. Doctor
No. of

Copies

R. M. Ecker

SEQUIM

J. W. Falco

J. M. Hales

S. H. Hall (5)

P. C. Hays

K6-78

K6- 04

$K 6-96$

K6-86

C. J. Hostetler

B. V. Johnston

S. P. Juracich (5)

$\mathrm{K} 6-81$

K6-86

R. L. Skaggs

K6-96

Publishing Coordination

Technical Report Files (5) 

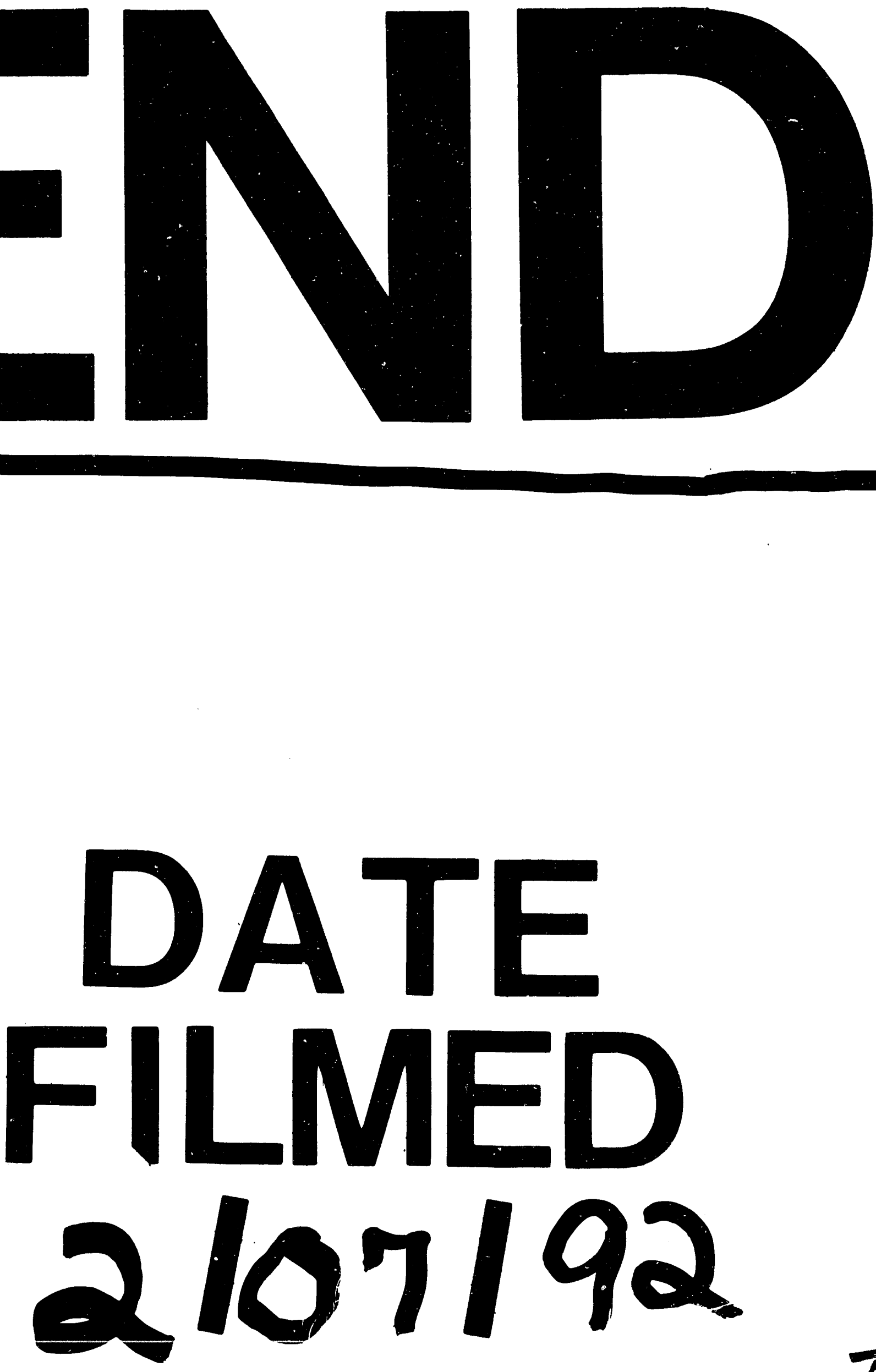
